\title{
Cladistics
}

Cladistics 31 (2015) 621-651

$10.1111 /$ cla. 12116

\section{0 million years of diversification: elucidating the patterns of orthopteran evolution based on comprehensive taxon and gene sampling}

\author{
Hojun Song ${ }^{\mathrm{a}, \mathrm{b}}$ *, Christiane Amédégnato ${ }^{\mathrm{c}}$, Maria Marta Cigliano ${ }^{\mathrm{d}}$, Laure Desutter- \\ Grandcolas $^{\mathrm{c}}$, Sam W. Heads ${ }^{\mathrm{e}}$, Yuan Huang ${ }^{\mathrm{f}}$, Daniel Otte ${ }^{\mathrm{g}}$ and Michael F. Whiting ${ }^{\mathrm{h}}$ \\ ${ }^{a}$ Department of Biology, University of Central Florida, Orlando, FL, USA; ${ }^{b}$ Department of Entomology, Texas A\&M University, College Station, \\ TX, USA; 'Département Systématique et Évolution, Muséum National d 'Histoire Naturelle', ISYEB, UMR7205 CNRS MNHN UPMC EPHE, \\ Paris, France; ${ }^{d}$ División Entomología, Museo de La Plata, La Plata, Argentina; ${ }^{e}$ Illinois Natural History Survey, University of Illinois at Urbana-

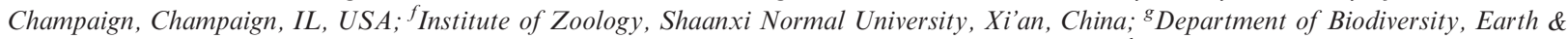 \\ Environmental Science, Academy of Natural Sciences of Drexel University, Philadelphia, PA, USA; ${ }^{h}$ Department of Biology and M. L. Bean \\ Museum, Brigham Young University, Provo, UT, USA
}

Accepted 4 February 2015

\begin{abstract}
Orthoptera is the most diverse order among the polyneopteran groups and includes familiar insects, such as grasshoppers, crickets, katydids, and their kin. Due to a long history of conflicting classification schemes based on different interpretations of morphological characters, the phylogenetic relationships within Orthoptera are poorly understood and its higher classification has remained unstable. In this study, we establish a robust phylogeny of Orthoptera including 36 of 40 families representing all 15 currently recognized superfamilies and based on complete mitochondrial genomes and four nuclear loci, in order to test previous phylogenetic hypotheses and to provide a framework for a natural classification and a reference for studying the pattern of divergence and diversification. We find strong support for monophyletic suborders (Ensifera and Caelifera) as well as major superfamilies. Our results corroborate most of the higher-level relationships previously proposed for Caelifera, but suggest some novel relationships for Ensifera. Using fossil calibrations, we provide divergence time estimates for major orthopteran lineages and show that the current diversity has been shaped by dynamic shifts of diversification rates at different geological times across different lineages. We also show that mitochondrial tRNA gene orders have been relatively stable throughout the evolutionary history of Orthoptera, but a major tRNA gene rearrangement occurred in the common ancestor of Tetrigoidea and Acridomorpha, thereby representing a robust molecular synapomorphy, which has persisted for $250 \mathrm{Myr}$.
\end{abstract}

(c) The Willi Hennig Society 2015.

\section{Introduction}

With more than 25700 extant species, Orthoptera is the most diverse order among the polyneopteran insect lineages (Grimaldi and Engel, 2005; Eades et al., 2014). The order includes familiar singing insects, such as crickets and katydids, as well as often devastating pests, such as grasshoppers and locusts (Gangwere

\footnotetext{
*Corresponding author:

E-mail address: hsong@tamu.edu
}

et al., 1997). Orthopteran insects have diversified into numerous lineages that occupy every conceivable terrestrial habitat outside the polar regions and play integral roles in the ecosystem (Uvarov, 1966; Kevan, 1982). Such diversity in form and function has attracted researchers who use these insects as model systems for studying anatomy, physiology, neurobiology, bioacoustics, chemical ecology, life-history traits, speciation research, and evolutionary ecology (Uvarov, 1966, 1977; Baccetti, 1987; Chapman and Joern, 1990; Gangwere et al., 1997; Pener and Simpson, 2009). 
The monophyly of Orthoptera is strongly supported by several morphological characters, such as the presence of the cryptopleuron and jumping hind legs among others (Kevan, 1982; Kristensen, 1991; Grimaldi and Engel, 2005), and the order is considered to be divided into two suborders: Ensifera (crickets, katydids, wetas, and their relatives) (Fig. 1) and Caelifera (grasshoppers, locusts, and their relatives) (Fig. 2). Despite the familiarity and the diversity of the group, the phylogenetic relationships within Orthoptera are poorly understood and its higher classification remains unstable due to a long history of conflicting taxonomic hypotheses based on different character sets, such as fossil wing venation (Zeuner, 1942; Sharov, 1968; Gorochov, 1995a), internal organs (Slifer, 1939; Judd, 1947; Dirsh, 1957; Baccetti, 1987), external morphology (Blackith and Blackith, 1968; Vickery and Kevan, 1983), and the male phallic complex (Chopard, 1920; Ander, 1939; Roberts, 1941; Dirsh, 1973; Amédégnato, 1974; Eades, 2000). Most of these hypotheses are precladistic and lack formal analyses, and there are major disagreements among even those based on the same set of morphological characters. In 1975, the higher classification of Orthoptera reached its most chaotic
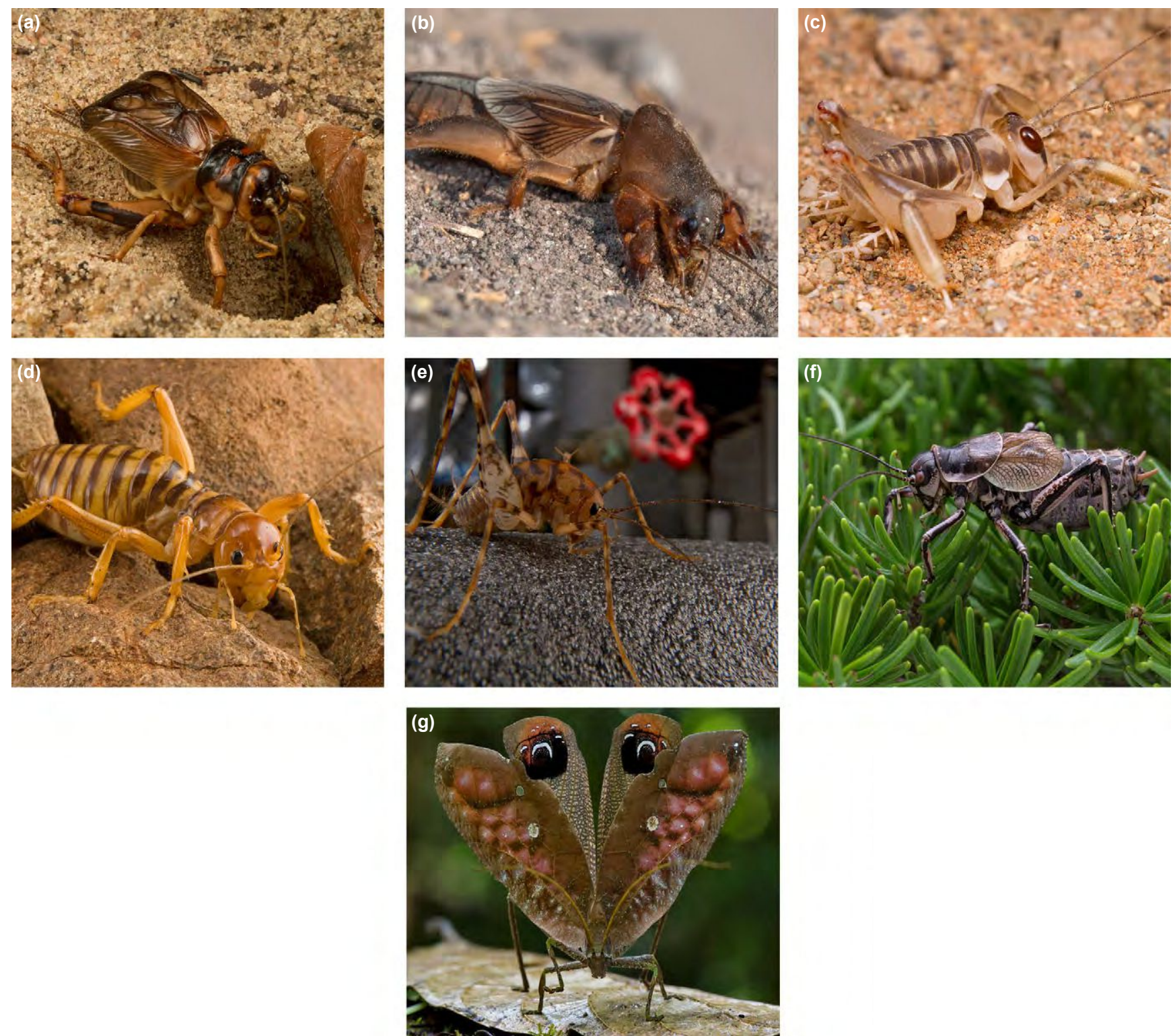

Fig. 1. Representatives of Ensifera. (a) Grylloidea: Gryllidae: Brachytrupes membranaceus; (b) Gryllotalpoidea: Gryllotalpidae: Gryllotalpa africana; (c) Schizodactyloidea: Schizodactylidae: Comicus capensis; (d) Stenopelmatoidea: Stenopelmatidae: Sia sp.; (e) Rhaphidophoroidea: Rhaphidophoridae: Diestrammena asynamora; (f) Hagloidea: Prophalangopsidae: Cyphoderris monstrosa; (g) Tettigonioidea: Tettigoniidae: Pterochroza ocellata (Photograph credit: Piotr Naskrecki). 

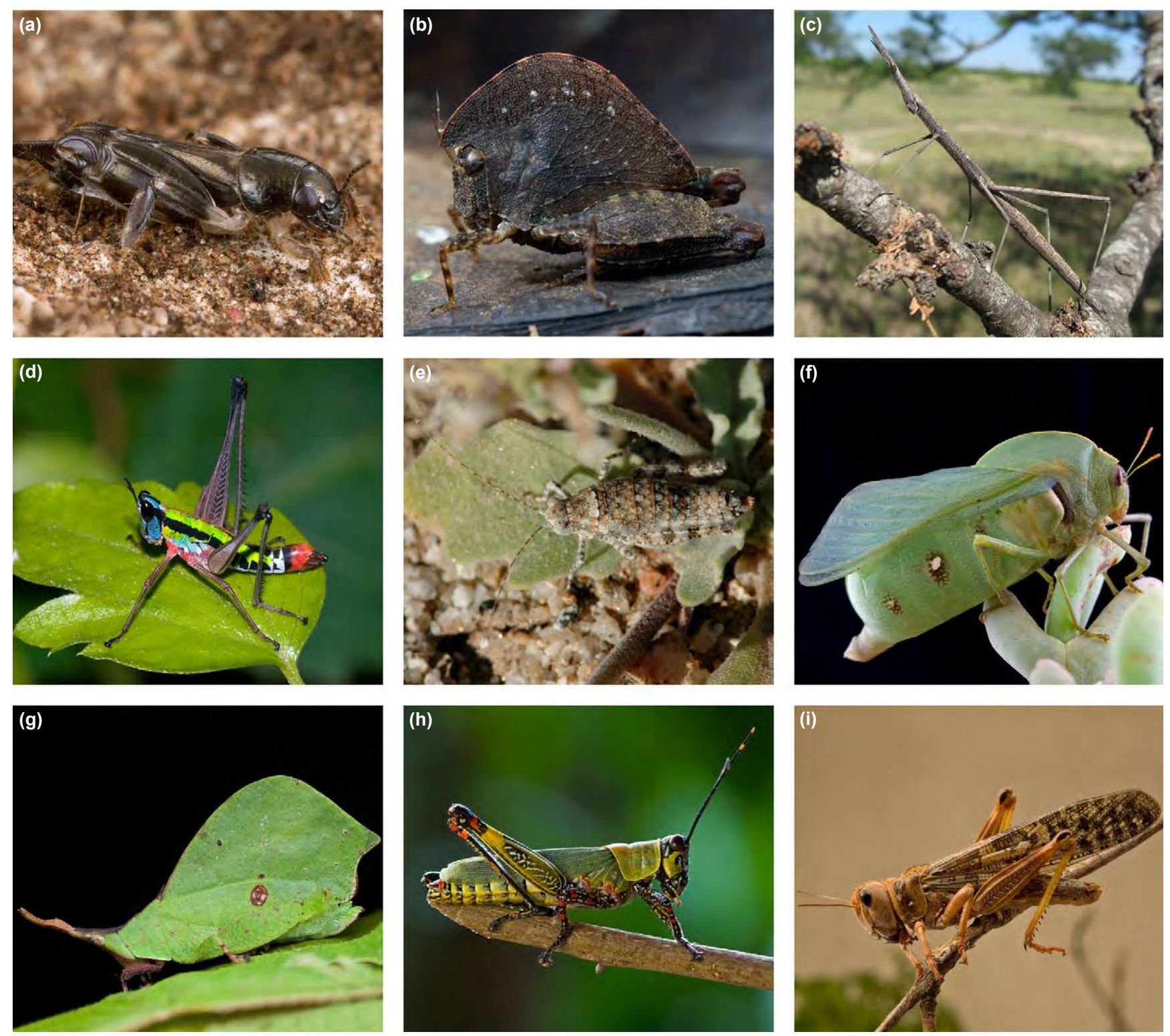

Fig. 2. Representatives of Caelifera. (a) Tridactyloidea: Tridactylidae: Xya sp.; (b) Tetrigoidea: Tetrigidae: Afrolarcus sp.; (c) Proscopioidea: Proscopiidae: Tetanorhynchus sp.; (d) Eumastacoidea: Episactidae: Episactus tristani; (e) Tanaoceroidea: Tanaoceridae: Tanaocerus koebelei; (f) Pneumoroidea: Pneumoridae: Bullacris sp.; (g) Trigonopterygoidea: Trigonopterygidae: Systella rafflesii; (h) Pyrgomorphoidea: Pyrgomorphidae: Zonocerus variegatus; (i) Acridoidea: Acrididae: Locustana pardalina (Photograph credit: Piotr Naskrecki [a, b, f, h, i], Paul Lenhart [c], Robert A. Behrstock [d], Hartmut Wisch [e], Kurt Orion G [g]).

state when Dirsh proposed a superorder Orthopteroidea with ten new orders (Dirsh, 1975). Although contemporary orthopterists agree that Dirsh's treatment was extreme (Gurney, 1976; Kevan, 1976), the aftermath of taxonomic instability still lingers today and many new species are being described under conflicting classification schemes (Song, 2010).

Several researchers have proposed different higher classification schemes for Orthoptera and the major lineages based on modern cladistic methods using morphology and molecules (Fig. 3). Flook et al. (1999) produced the first modern phylogeny of Orthoptera based on 31 ingroup taxa representing all major lineages and three ribosomal loci, and redefined some superfamily concepts. Due to small taxon and character sampling, however, some of the relationships were not fully resolved, but this work still stands as the most comprehensive work for the entire order until now. In recent years, a number of studies used complete mitochondrial genome (mtgenome) sequences to infer the phylogeny of Orthoptera (Fenn et al., 2008; Sheffield et al., 2010; Zhou et al., 2010; Zhang et al., 


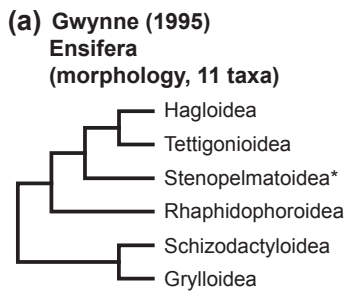

(d) Flook et al. (2000) Acridomorpha (16S, 12S \& 18S, 18 taxa)

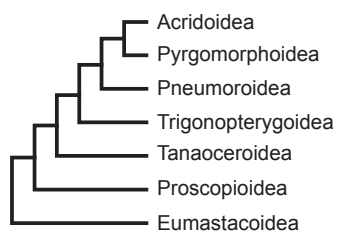

(f) Jost \& Shaw (2006) Ensifera (16S, 18S \& 28S, 51 taxa)

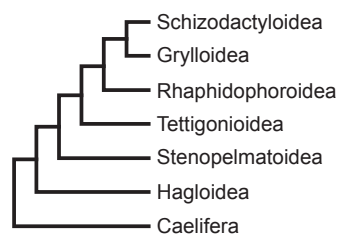

(i) Zhang et al. (2013a) Orthoptera (NADH genes, 49 taxa)

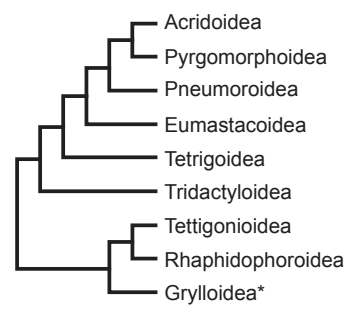

(b) Flook \& Rowell (1997) Caelifera

(16S \& 12S, 38 taxa)

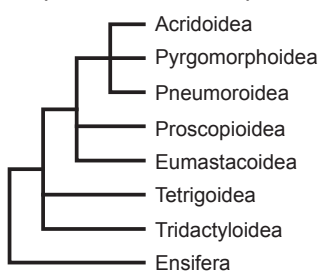

(e) Desutter-Grandcolas (2003) Ensifera

(morphology, 14 taxa)

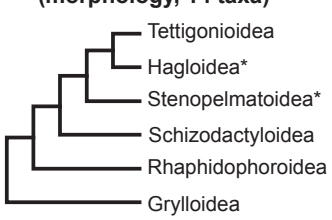

(g) Zhou et al. (2010) Orthoptera (mtgenome, 22 taxa)

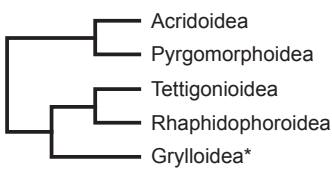

(j) Leavitt et al. (2013) Acridomorpha (mtgenome, 44 taxa)

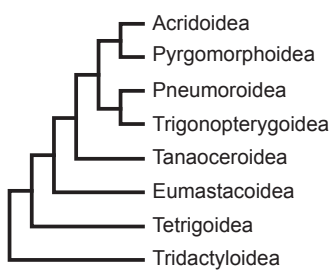

(c) Flook et al. (1999) Orthoptera (16S, 12S \& 18S, 35 taxa)

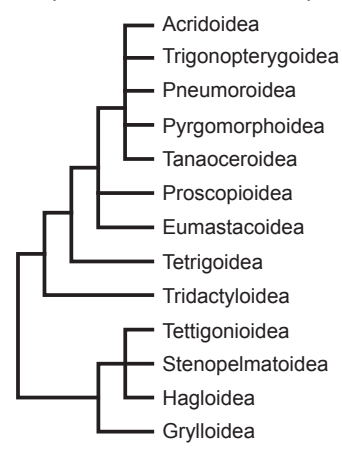

(h) Sheffield et al. (2010) Orthoptera (mtgenome, 23 taxa)

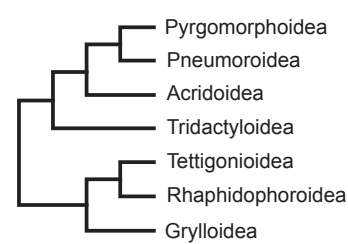

(k) Zhou et al. (2014) Ensifera (mtgenome, 17 taxa)

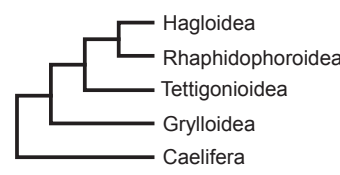

Fig. 3. Previous phylogenetic hypotheses of Orthoptera based on modern cladistic methods. Nodes from the original studies have been collapsed to show superfamily-level relationships. Asterisks represent superfamilies sensu Eades et al. (2014) that were not found to be monophyletic in the original studies.

2013a), but most of these had a relatively small taxon sampling often based only on available mtgenome data, not enough to seriously test previous classification schemes. At the level of suborders, Gwynne (1995) presented the first explicit cladistic analysis of Ensifera based on morphological characters coded from the taxonomic literature and used it to address the evolution of acoustic communication and mating behaviour in Ensifera. Nevertheless, this study also met with some sharp criticisms based on methodological grounds (Nickle and Naskrecki, 1997; DesutterGrandcolas, 2003). Desutter-Grandcolas (2003) coded 85 morphological characters from 12 ensiferan terminals (three emblematic genera and nine families), which resulted in a well-resolved phylogeny, but this taxon sampling did not allow generalizations to be made about ensiferan evolution because polymorphism was included in the data matrix. Jost and Shaw (2006) then reconstructed the phylogeny of Ensifera based on three ribosomal loci and 51 terminals, which resulted in a radically different phylogenetic relationship from previous hypotheses, but the dataset used in this work was later shown to be highly sensitive to different analytical methods (Legendre et al., 2010). Zhou et al. (2014) presented a mtgenome phylogeny of Ensifera based on a newly sequenced mtgenome of Prophalangopsidae (representing Hagloidea) and available ensiferan mtgenomes, but the study lacked several key taxa from basal ensiferans to make a significant impact. As for Caelifera, Flook and Rowell (1997) proposed the 
Table 1

Taxonomic information and Genbank accession numbers for 258 taxa used in total evidence analysis

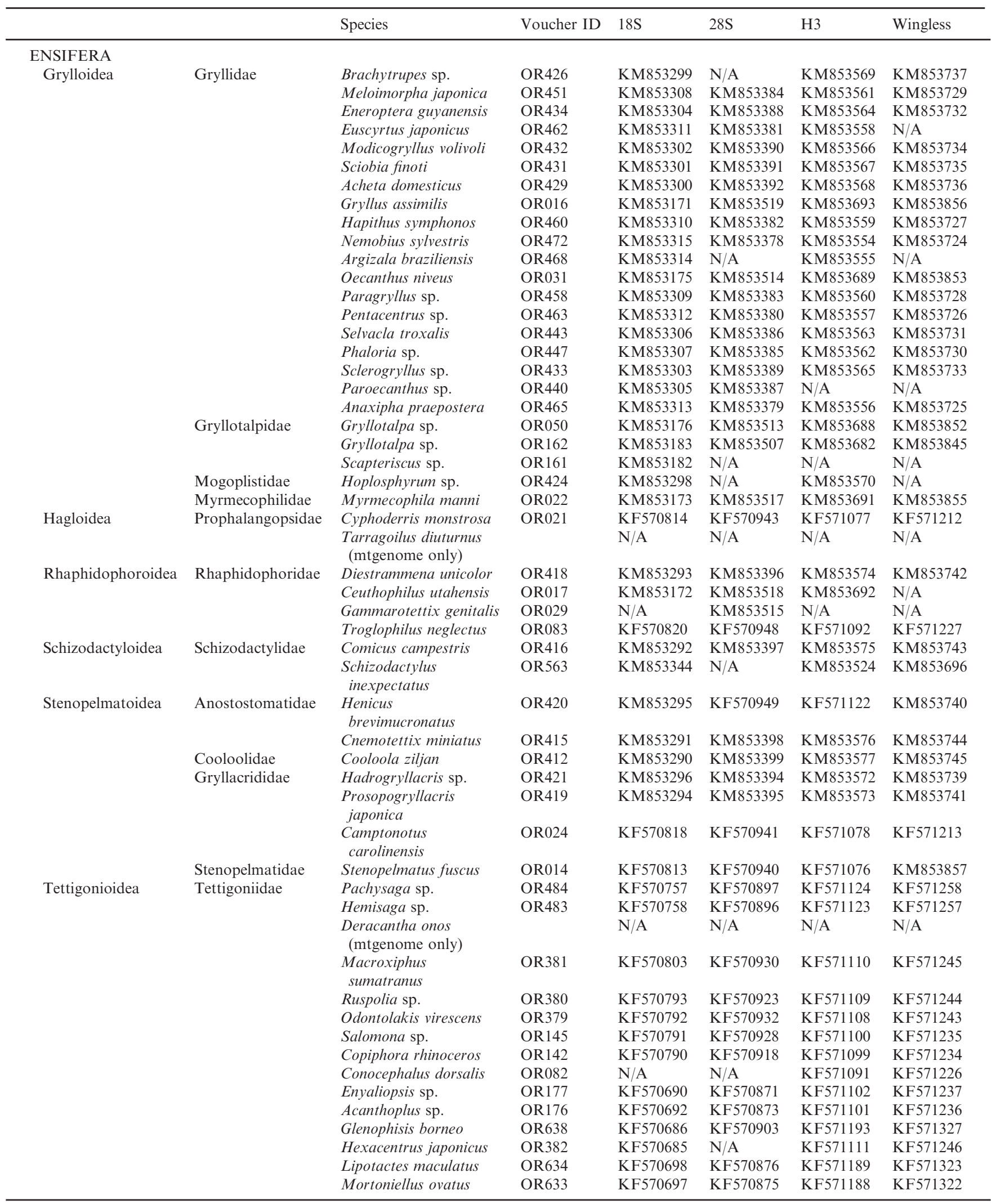


Table 1

(Continued)

\begin{tabular}{|c|c|c|c|c|c|c|c|}
\hline & & Species & Voucher ID & $18 \mathrm{~S}$ & $28 \mathrm{~S}$ & H3 & Wingless \\
\hline \multirow{23}{*}{ Tettigonioidea } & & Arachnoscelis rehni & OR582 & KF570695 & KF570900 & KF571139 & KF571273 \\
\hline & & Alloteratura sp. & OR636 & KF570703 & KF570878 & KF571191 & KF571325 \\
\hline & & $\begin{array}{l}\text { Xizicus fascipes } \\
\text { (mtgenome only) }\end{array}$ & & $\mathrm{N} / \mathrm{A}$ & $\mathrm{N} / \mathrm{A}$ & $\mathrm{N} / \mathrm{A}$ & $\mathrm{N} / \mathrm{A}$ \\
\hline & & $\begin{array}{l}\text { Mecopoda elongata } \\
\text { (mtgenome only) }\end{array}$ & & $\mathrm{N} / \mathrm{A}$ & $\mathrm{N} / \mathrm{A}$ & $\mathrm{N} / \mathrm{A}$ & $\mathrm{N} / \mathrm{A}$ \\
\hline & & Zitsikama tessellata & OR384 & KF570756 & KF570881 & KF571112 & KF571247 \\
\hline & & Phylloptera sp. & OR388 & KF570858 & KM853413 & KF571116 & KF571251 \\
\hline & & Eurycophora sp. & OR387 & KF570743 & KF570863 & KF571115 & KF571250 \\
\hline & & Dysonia sp. & OR386 & KF570722 & KF570849 & KF571114 & KF571249 \\
\hline & & Trigonocorypha sp. & OR378 & KF570745 & KF570844 & KF571107 & KF571242 \\
\hline & & Phaneroptera falcata & OR076 & KF570718 & KF570864 & KF571088 & KF571223 \\
\hline & & Phasmodes sp. & OR485 & KF570817 & KF570944 & KF571125 & KF571259 \\
\hline & & Phyllophora sp. & OR132 & KF570816 & KF570911 & KF571096 & KF571231 \\
\hline & & Sasima sp. & OR131 & KF570770 & KF570910 & KF571095 & KF571230 \\
\hline & & Phrictaetypus viridis & OR393 & KF570772 & KF570909 & KF571121 & KF571256 \\
\hline & & Pantecphylus sp. & OR392 & KF570707 & KF570823 & KF571120 & KF571255 \\
\hline & & Teleutias sp. & OR391 & KF570815 & KF570829 & KF571119 & KF571254 \\
\hline & & Idiarthron sp. & OR389 & KF570712 & KF570827 & KF571117 & KF571252 \\
\hline & & Panoploscelus sp. & OR377 & KF570713 & KF570826 & KF571106 & KF571241 \\
\hline & & Typophyllum sp. & OR196 & KF570693 & KF570946 & KF571103 & KF571238 \\
\hline & & Cymatomera sp. & OR139 & KF570779 & KF570885 & KF571098 & KF571233 \\
\hline & & Zabalius ophthalmicus & OR138 & KF570884 & KF570975 & KF571369 & KM853848 \\
\hline & & Tympanophora sp. & OR486 & KF570777 & KF570947 & KF571126 & KF571260 \\
\hline & & Kawanaphila sp. & OR487 & KF570700 & KF570882 & KF571127 & KF571261 \\
\hline \multicolumn{8}{|l|}{ CAELIFERA } \\
\hline \multirow[t]{13}{*}{ Acridoidea } & Acrididae & Truxalis sp. & OR510 & KM853325 & KM853367 & KM853543 & KM853714 \\
\hline & & Hyalopteryx rufipennis & OR240 & KM853210 & KM853480 & KM853655 & KM853819 \\
\hline & & $\begin{array}{l}\text { Calephorus } \\
\text { compressiocornis }\end{array}$ & OR192 & KM853192 & KM853498 & KM853673 & KM853836 \\
\hline & & Acrida willemsei & OR059 & KM853177 & KM853512 & KM853687 & KM853851 \\
\hline & & $\begin{array}{l}\text { Phlaeoba albonema } \\
\text { (mtgenome only) }\end{array}$ & & $\mathrm{N} / \mathrm{A}$ & $\mathrm{N} / \mathrm{A}$ & $\mathrm{N} / \mathrm{A}$ & $\mathrm{N} / \mathrm{A}$ \\
\hline & & $\begin{array}{l}\text { Paracaloptenus } \\
\text { caloptenoides }\end{array}$ & OR194 & KM853194 & KM853496 & KM853671 & KM853834 \\
\hline & & Calliptamus barbarus & OR193 & KM853193 & KM853497 & KM853672 & KM853835 \\
\hline & & Kinangopa jeanelli & OR574 & KM853345 & KM853348 & KM853523 & KM853695 \\
\hline & & Aresceutica morogorica & OR506 & KM853322 & KM853371 & KM853547 & KM853717 \\
\hline & & Pezocatantops sp. & OR505 & KM853321 & KM853372 & KM853548 & KM853718 \\
\hline & & Urnisiella rubropunctata & OR499 & KM853320 & KM853373 & KM853549 & KM853719 \\
\hline & & $\begin{array}{l}\text { Stenocatantops } \\
\text { vitripennis }\end{array}$ & OR498 & KM853319 & KM853374 & KM853550 & KM853720 \\
\hline & & Rusurplia tristis & OR497 & KM853318 & KM853375 & KM853551 & KM853721 \\
\hline
\end{tabular}


Table 1

(Continued)

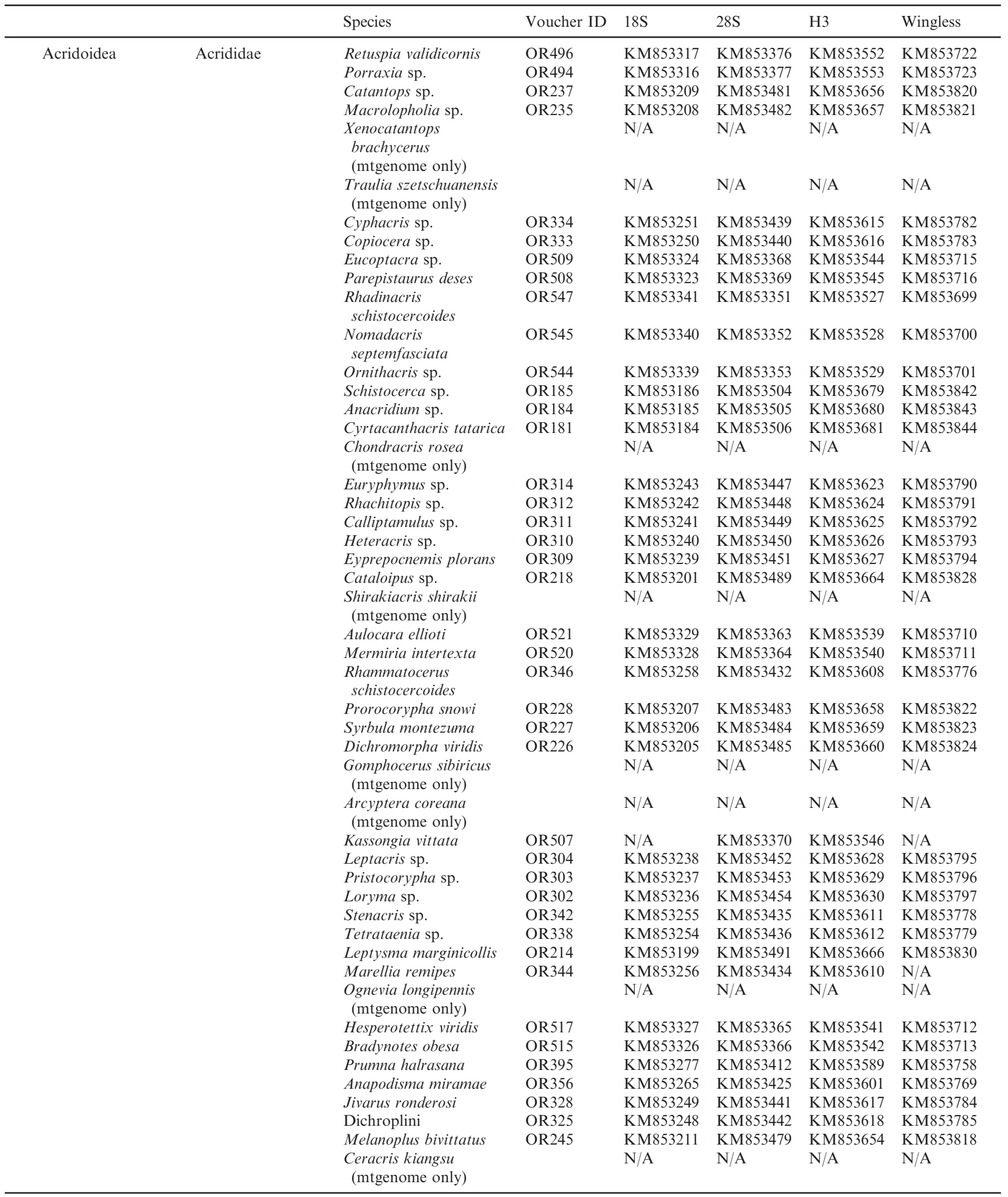


Table 1

(Continued)

\begin{tabular}{|c|c|c|c|c|c|c|c|}
\hline & & Species & Voucher ID & $18 \mathrm{~S}$ & $28 \mathrm{~S}$ & $\mathrm{H} 3$ & Wingless \\
\hline \multirow{33}{*}{ Acridoidea } & & Psinidia fenestralis & OR522 & KM853330 & KM853362 & KM853538 & KM853709 \\
\hline & & Heteropternis sp. & OR225 & KM853204 & KM853486 & KM853661 & KM853825 \\
\hline & & Locusta migratoria & OR191 & KM853191 & KM853499 & KM853674 & KM853837 \\
\hline & & Xanthippus sp. & OR 187 & KM853188 & KM 853502 & KM853677 & KM 853840 \\
\hline & & Trimerotropis sp. & OR 186 & KM853187 & KM853503 & KM853678 & KM853841 \\
\hline & & Locheuma brunneri & OR366 & KM853268 & KM853422 & KM853598 & KM853766 \\
\hline & & $\begin{array}{l}\text { Ommatolampis } \\
\text { quadrimaculata }\end{array}$ & OR364 & KM853267 & KM 853423 & KM853599 & KM853767 \\
\hline & & Aspidophyma americana & OR361 & KM853266 & KM853424 & KM853600 & KM853768 \\
\hline & & Paulinia acuminata & OR345 & KM853257 & KM853433 & KM853609 & KM853777 \\
\hline & & Poecilocloeus napoana & OR368 & KM853270 & KM853420 & KM853596 & $\mathrm{N} / \mathrm{A}$ \\
\hline & & Coscineuta sp. & OR249 & KM853212 & KM853478 & KM853653 & KM853817 \\
\hline & & Galidacris variabilis & OR371 & KM853271 & KM853419 & KM853595 & KM853764 \\
\hline & & Paropaon sp. & OR337 & KM853253 & KM853437 & KM853613 & KM 853780 \\
\hline & & Spathosternum sp. & OR224 & KM853203 & KM853487 & KM853662 & KM853826 \\
\hline & & Petamella prosternalis & OR560 & KM853343 & KM853349 & KM853525 & KM853697 \\
\hline & & Tristria discoidalis & OR543 & KM853338 & KM853354 & KM853530 & KM853702 \\
\hline & Lentulidae & $\begin{array}{l}\text { Rhainopomona } \\
\text { magnificum }\end{array}$ & OR539 & KM853336 & KM853356 & KM853532 & $\mathrm{N} / \mathrm{A}$ \\
\hline & & Usambilla olivacea & OR538 & KM853335 & KM853357 & KM853533 & KM853704 \\
\hline & & Betiscoides sp. & OR296 & KM853235 & KM853455 & KM853631 & KM853798 \\
\hline & & Lentula callani & OR295 & KM853234 & KM853456 & KM853632 & KM853799 \\
\hline & & $\begin{array}{l}\text { Filchnerella } \\
\text { helanshanensis } \\
\text { (mtgenome only) }\end{array}$ & & $\mathrm{N} / \mathrm{A}$ & $\mathrm{N} / \mathrm{A}$ & $\mathrm{N} / \mathrm{A}$ & $\mathrm{N} / \mathrm{A}$ \\
\hline & & $\begin{array}{l}\text { Asiomethis zacharjini } \\
\text { (mtgenome only) }\end{array}$ & & $\mathrm{N} / \mathrm{A}$ & $\mathrm{N} / \mathrm{A}$ & $\mathrm{N} / \mathrm{A}$ & $\mathrm{N} / \mathrm{A}$ \\
\hline & & $\begin{array}{l}\text { Thrinchus schrenkii } \\
\text { (mtgenome only) }\end{array}$ & & $\mathrm{N} / \mathrm{A}$ & $\mathrm{N} / \mathrm{A}$ & $\mathrm{N} / \mathrm{A}$ & $\mathrm{N} / \mathrm{A}$ \\
\hline & Pamphagodidae & $\begin{array}{l}\text { Hemicharilaus } \\
\text { monomorphus }\end{array}$ & OR540 & KM853337 & KM853355 & KM853531 & KM853703 \\
\hline & Pyrgacrididae & Pyrgacris descampsi & OR317 & KM853246 & KM853444 & KM853620 & KM853787 \\
\hline & Romaleidae & $\begin{array}{l}\text { Megacheilacris } \\
\text { graminicola }\end{array}$ & OR355 & KM853264 & KM853426 & KM853602 & KM853770 \\
\hline & & Aphanolampis aberrans & OR354 & KM853263 & KM853427 & KM853603 & KM853771 \\
\hline & & Pseudonautia sp. & OR353 & KM853262 & KM853428 & KM853604 & KM853772 \\
\hline & & Lagarolampis amazonica & OR352 & KM853261 & KM853429 & KM853605 & KM853773 \\
\hline & & $\begin{array}{l}\text { Hyleacris } \\
\text { rubrogranulata }\end{array}$ & OR350 & KM853260 & KM853430 & KM853606 & KM853774 \\
\hline & & Aeolacris octomaculata & OR376 & KM853276 & KM853414 & KM853590 & KM853759 \\
\hline & & Agriacris magnifica & OR375 & KM853275 & KM853415 & KM853591 & KM853760 \\
\hline & & Maculiparia rotundata & OR374 & KM853274 & KM853416 & KM853592 & KM853761 \\
\hline
\end{tabular}


Table 1

(Continued)

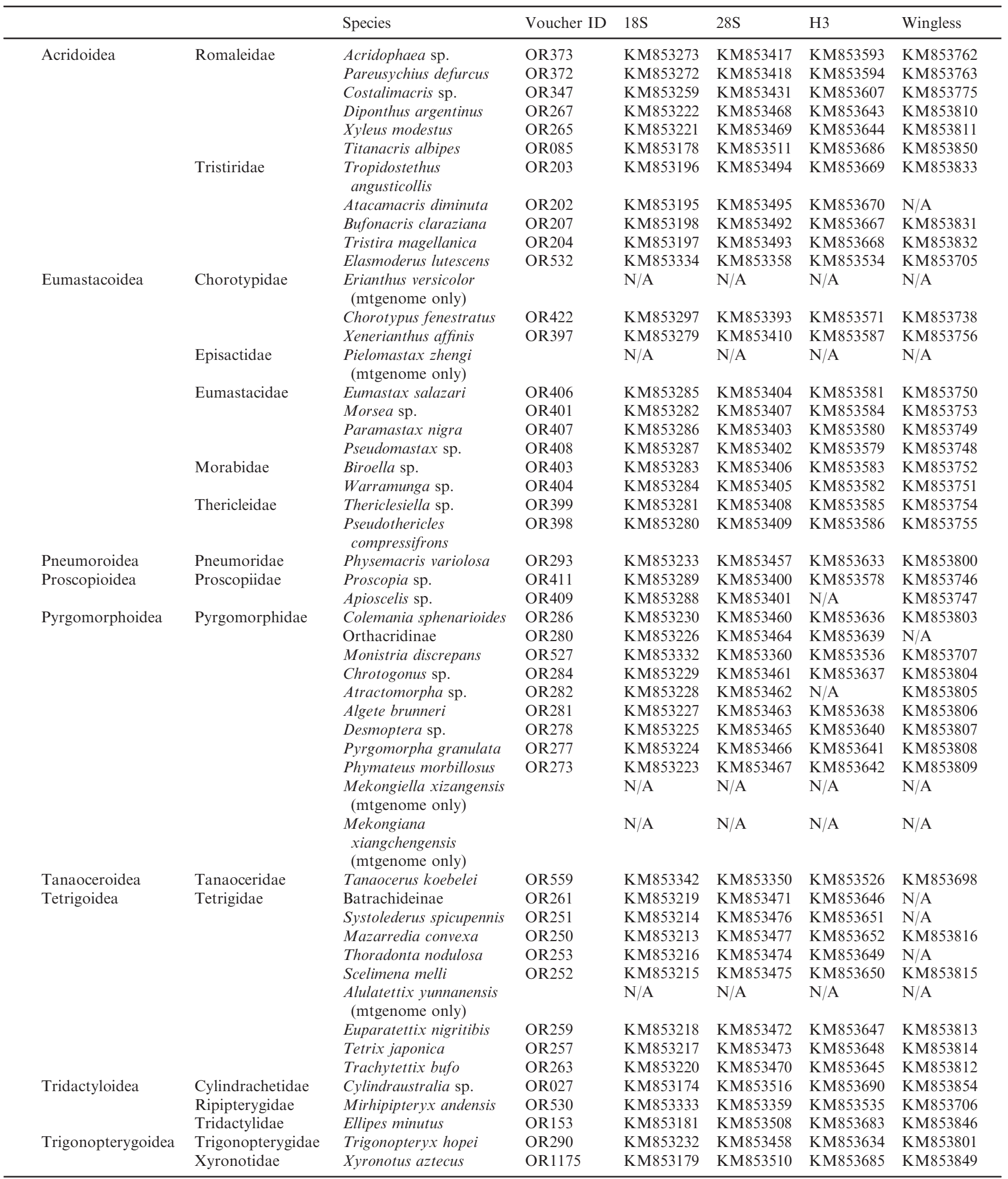


Table 1

(Continued)

\begin{tabular}{|c|c|c|c|c|c|c|c|}
\hline & & Species & Voucher ID & $18 \mathrm{~S}$ & $28 \mathrm{~S}$ & $\mathrm{H} 3$ & Wingless \\
\hline Grylloblattodea & Grylloblattidae & Grylloblatta sculleni & & DQ457301 & KM 853520 & KM853694 & $\mathrm{N} / \mathrm{A}$ \\
\hline Mantodea & Mantidae & Tamolanica tamolana & & EF383483 & EF383645 & GU064764 & FJ802940 \\
\hline Phasmatodea & Timematidae & Timema californicum & & KM853346 & KM853347 & KM853521 & $\mathrm{N} / \mathrm{A}$ \\
\hline
\end{tabular}

Taxonomic classification used in this table follows the Orthoptera Species File. Voucher ID corresponds to Brigham Young University Insect Genomic Collection (BYU-IGC) ID numbers. Specific collecting information and other additional information is provided in Table S1.

first phylogeny of the suborder based on 32 ingroup taxa representing all major lineages and two mitochondrial ribosomal genes, but this dataset was not sufficient enough to resolve the basal relationships. Flook et al. (2000) studied the phylogenetic relationships among the lower caeliferans based on a slightly more expanded taxon sampling and redefined some superfamily concepts. Leavitt et al. (2013) conducted a thorough analysis of mtgenome data across major caeliferan superfamilies, but their taxon sampling was more biased toward Acridoidea than other lineages. All of these previous studies were lacking either in taxon or character sampling, and resulted in conflicting higher classification schemes. Therefore, a well-resolved higher-level phylogeny of Orthoptera is desperately needed.

The main objective of this research is to fill the void in the study of Orthoptera by establishing a robust phylogeny of Orthoptera based on comprehensive taxon and character sampling to provide a framework for natural classification and a reference for studying interesting evolutionary patterns within the order. We present a large-scale molecular phylogeny of Orthoptera based on 254 ingroup taxa and complete mtgenome data and nuclear genes. Using our phylogeny, we test previous phylogenetic hypotheses and propose a new classification scheme for the group. Using strongly corroborated fossil evidence, we present divergent time estimates for major orthopteran lineages and also explore whether different lineages have undergone different tempos of diversification throughout $300 \mathrm{Myr}$ of evolution. Furthermore, we explore the evolution of mitochondrial gene rearrangements across the order based on complete mtgenome sequences.

\section{Materials and methods}

\section{Taxon and character sampling}

In this study, we generally used the classification scheme adopted by the Orthoptera Species File (Eades et al., 2014) in order to test it with our phylogenetic analysis. One exception was in the case of Tettigonioidea, in which we recognized only a single family Tettigoniidae, as no alternative hypothesis based on well-corroborated monophyletic groups have been proposed. We sampled a total of 254 taxa covering the phylogenetic diversity within Orthoptera, which represents the most comprehensive taxon sampling for this group to date (Table 1). Specifically, we included extant representatives from all 15 currently recognized orthopteran superfamilies (six ensiferan and nine caeliferan) representing all 12 ensiferan families and 24 out of 28 caeliferan families (Eades et al., 2014). We were not able to obtain DNA-grade samples for four families, which were Dericorythidae, Euschmidtiidae, Lathiceridae, and Mastacideidae. For outgroup taxa, we included four polyneopteran species, Grylloblatta sculleni (Grylloblattodea), Tamolanica tamolana (Mantodea), Timema californicum (Phasmatodea), and Sclerophasma paresisense (Mantophasmatodea). For 69 terminals, which represented key taxa for understanding higher-level relationships, we included complete mtgenome data, ten of which were newly sequenced for this study. The remaining mtgenomes were either previously generated by us (Fenn et al., 2007, 2008; Sheffield et al., 2010; Leavitt et al., 2013) or obtained from GenBank (Table 2). For all taxa, we generated complete $18 \mathrm{~S}$ and $28 \mathrm{~S}$ ribosomal RNA sequences and two conserved nuclear protein-coding genes, histone 3 and wingless, all of which have been frequently used for higher-level insect phylogenetics (Flook et al., 1999; Whiting, 2002; Whiting et al., 2003; Svenson and Whiting, 2004; Jost and Shaw, 2006). For the 26 taxa for which we obtained mtgenome sequences from GenBank, we were not able to generate the other four genes due to an obvious lack of access to specimens. The DNA-grade tissue samples used for this study were either collected by the authors or provided by collaborators. They were preserved in $100 \%$ ethanol and vouchered to the $-80{ }^{\circ} \mathrm{C}$ cryofacility in the Insect Genomic Collection at Brigham Young University (BYU-IGC). We followed standard protocols for DNA extraction, polymer chain reaction (PCR), 
sequencing, and primer walking for mtgenome sequencing, which we described in detail elsewhere (Sheffield et al., 2010; Leavitt et al., 2013; Mugleston et al., 2013). All newly generated mtgenomes were first uploaded as raw fasta files to MITOS (Bernt et al., 2013) to identify open reading frames (ORFs) and tRNAs. The initial MITOS annotation was used as a guideline to delimit gene boundaries and start and stop codons of each protein-coding gene were manually identified in Sequencher 4.8 (GeneCode), following the recommendation by Cameron (2014a). The annotations for the 10 newly sequenced mtgenomes are presented in Table S1. The DNA sequence data generated for this study are deposited to GenBank with accession numbers: KM657331-KM657340 (mtgenomes) and KM853171-KM853857 (nuclear genes).

\section{Phylogenetic analyses}

We employed several alignment strategies for different loci in our dataset. For both mitochondrial and nuclear protein-coding genes, we aligned based on the conservation of reading frames by first translating into amino acids in MEGA 5 (Tamura et al., 2011), aligning individually in MUSCLE (Edgar, 2004) using default parameters, and back-translating to nucleotides. The tRNA sequences were individually aligned in MUSCLE using default parameters. Mitochondrial ribosomal RNA (16S and 12S) genes were first aligned using E-INS-i strategy in MAFFT (Katoh et al., 2005). Then, we used predicted secondary structures of $16 \mathrm{~S}$ and $12 \mathrm{~S}$ of Locusta migratoria in RNAfold WebServer (http://rna.tbi.univie.ac.at/cgi-bin/RNAfold.cgi) as input constraint files to perform secondary structure-based alignment in RNAsalsa (Stocsits et al., 2009). For nuclear ribosomal RNA (18S and 28S) genes, we first aligned using E-INS-i strategy in MAFFT and used GBlocks 0.91b (Castresana, 2000), while allowing gap positions within the final blocks. All these individual alignments were concatenated into a single matrix in MacClade 4 (Maddison and Maddison, 2005), with the data divided into a total of 71 data blocks (15 protein-coding genes divided into individual codon positions, 22 tRNAs, and two mitochondrial and two nuclear ribosomal genes). We then used PartitionFinder (Lanfear et al., 2012) using the "greedy" algorithm (heuristic search) with branch lengths estimated as "unlinked" to search for the bestfit scheme as well as to estimate the model of nucleotide evolution for each partition.

We performed two separate phylogenetic analyses differing in taxon and character sampling strategies. The first analysis was based on the complete mtgenome data (16 758 aligned bp) from 69 taxa to establish deep relationships within Orthoptera, which was also used for a divergence time estimate analysis. The second analysis was based on the total evidence dataset (21 025 aligned bp and 258 taxa), which represented a taxon-rich analysis, but had heterogeneously missing data. For 189 of 258 taxa, we did not have mtgenome data, and for 26 taxa, we did not have nuclear gene data. The rationale behind this second analysis was that the mtgenome data would establish robust "backbone" relationships, while the taxa without mtgenome data would still be able to form accurate phylogenetic relationships based on four nuclear genes.

We used parsimony and maximum likelihood (ML) inference methods to reconstruct the phylogeny of Orthoptera. For the parsimony analyses, we used TNT (Goloboff et al., 2003) using New Technology Search options with gaps treated as missing. We first reset RAM to 1000 Mbytes, held 1000000 trees, and set Grylloblatta as a root prior to tree search. The minimum length was searched ten times using ratchet (Nixon, 1999), sectorial search, drift, and tree fusing (Goloboff, 1999) under default parameters and by setting random seed as 0 and the initial driven search level at 15. Bootstrap support values were calculated to assess nodal support. For the ML analyses, we used the best-fit partitioning scheme recommended by PartitionFinder with the GTRGAMMA model applied to each partition and analysed using RAxML 7.2.8 (Stamatakis et al., 2008) on XSEDE (Extreme Science and Engineering Discovery Environment, https://www.xsede.org) through CIPRES Science Gateway (Miller et al., 2011). Nodal support was evaluated using 5000 replications of rapid bootstrapping implemented in RAxML. The resulting trees were visualized using FigTree (Rambaut, 2006-2009) and iTOL (Letunic and Bork, 2011). Our aligned datasets and the resulting trees were deposited to Dryad (doi: 10.5061/ dryad.96r8b).

\section{Topology test}

In order to statistically test the previous phylogenetic hypotheses against our results, we performed the Shimodaira-Hasegawa (SH) test (Shimodaira and Hasegawa, 1999) and the approximately unbiased (AU) test (Shimodaira, 2002). We ran two rounds of the topological tests, one for the mtgenome analysis and another for the total evidence data. For the mtgenome phylogeny, we first obtained the best likelihood score from the ML analysis. Then, we ran three separate ML analyses using topological constraints that matched (i) the caeliferan superfamily-level relationships proposed by Flook et al. $(1999,2000)$, and the ensiferan relationships proposed by (ii) DesutterGrandcolas (2003), and (iii) Jost and Shaw (2006). When making these constraints, unconstrained relationships were left as polytomy. Using the best trees 
Table 2

Taxonomic information and Genbank accession numbers for taxa used in mtgenome analysis

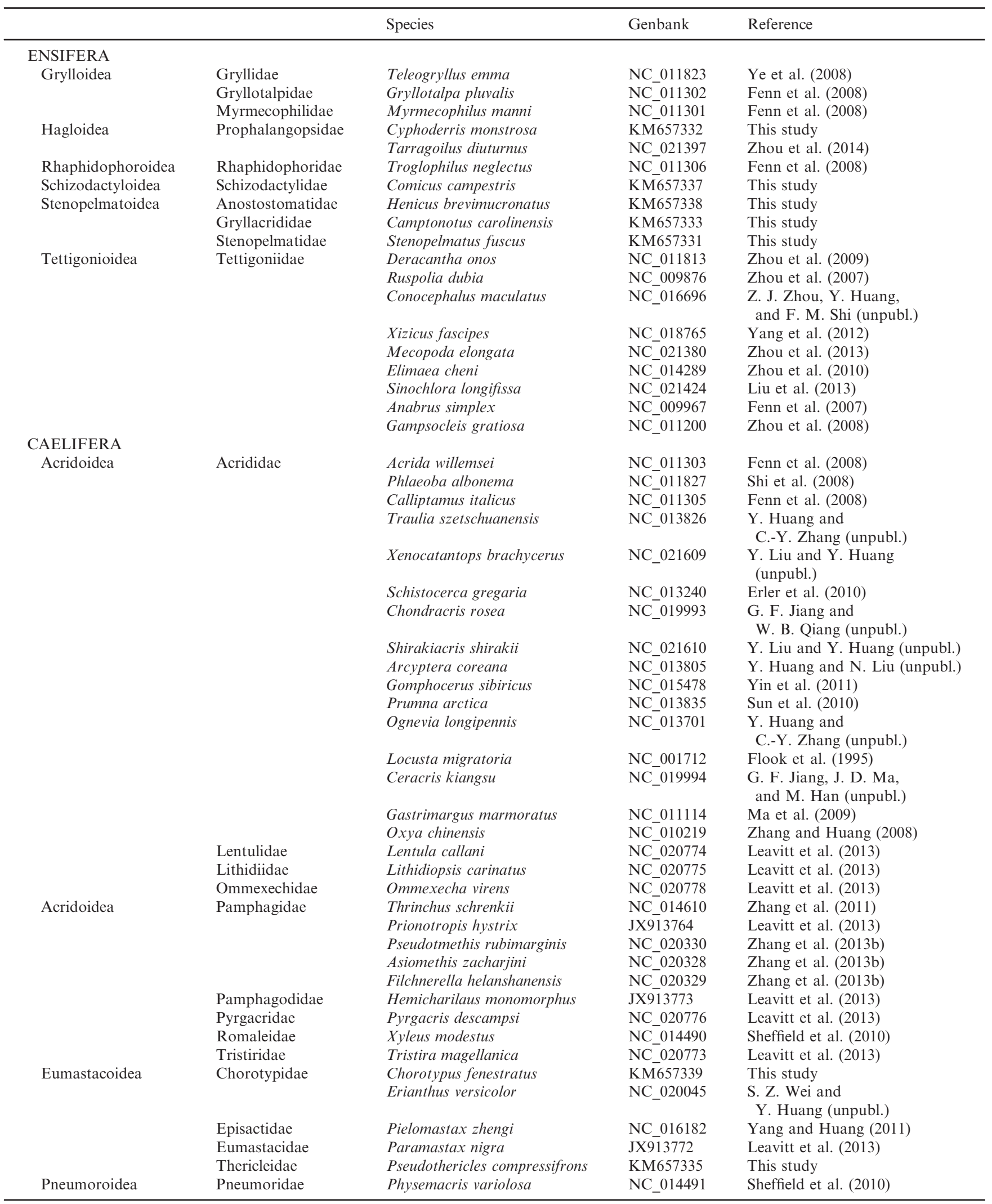




\begin{tabular}{|c|c|c|c|c|}
\hline & & Species & Genbank & Reference \\
\hline Proscopioidea & Proscopiidae & Proscopia sp. & KM657336 & This study \\
\hline \multirow[t]{3}{*}{ Pyrgomorphoidea } & \multirow[t]{3}{*}{ Pyrgomorphidae } & Atractomorpha sinensis & NC_011824 & Ding et al. (2007) \\
\hline & & Mekongiella xizangensis & NC_-014451 & Zhao et al. (2010) \\
\hline & & Mekongiana xiangchengensis & NC_-014450 & Zhao et al. (2010) \\
\hline Tanaoceroidea & Tanaoceridae & Tanaocerus koebelei & NC_020777 & Leavitt et al. (2013) \\
\hline \multirow[t]{3}{*}{ Tetrigoidea } & \multirow[t]{3}{*}{ Tetrigidae } & Tetrix japonica & NC_018543 & Xiao et al. (2012a) \\
\hline & & Alulatettix yunnanensis & NC_018542 & Xiao et al. (2012b) \\
\hline & & Trachytettix bufo & JX913766 & Leavitt et al. (2013) \\
\hline \multirow[t]{3}{*}{ Tridactyloidea } & Cylindrachetidae & Cylindraustralia $\mathrm{sp}$. & KM657334 & This study \\
\hline & Ripipterygidae & Mirhipipteryx andensis & KM657340 & This study \\
\hline & Tridactylidae & Ellipes minuta & NC_014488 & Sheffield et al. (2010) \\
\hline Trigonopterygoidea & Trigonopterygidae & Trigonopteryx hopei & JX913767 & Leavitt et al. (2013) \\
\hline \multicolumn{5}{|l|}{ OUTGROUP } \\
\hline Grylloblattodea & Grylloblattidae & Grylloblatta sculleni & DQ241796 & Cameron et al. (2006) \\
\hline Mantodea & Mantidae & Tamolanica tamolana & NC_007702 & Cameron et al. (2006) \\
\hline Mantophasmatodea & Mantophasmatidae & Sclerophasma paresisense & NC_007701 & Cameron et al. (2006) \\
\hline Phasmatodea & Timematidae & Timema californicum & DQ2441799 & Cameron et al. (2006) \\
\hline
\end{tabular}

Taxonomic classification used in this table follows the Orthoptera Species File.

from these analyses, we calculated per-site log-likelihood score for each tree in RAxML using the $-\mathrm{f} g$ option, which we used as input data to obtain $P$-values for the SH and the AU tests in CONSEL (Shimodaira and Hasegawa, 2001). For the total evidence phylogeny, we ran four separate ML analyses using the topological constraints that matched the three abovementioned studies as well as the mtgenome phylogeny, and performed the tests using the same procedure.

\section{Divergence time estimate analysis}

In order to estimate timing and rates of divergence across major orthopteran lineages using abundant fossil records, we performed a divergence time estimate analysis using BEAST v.1.8 (Drummond et al., 2012). For this analysis, we used the 69-taxa dataset based on the complete mtgenome data using the partitioning scheme and the models of nucleotide evolution recommended by PartitionFinder. We created an xml file in BEAUti (Drummond et al., 2012), specifying the starting tree, fossil priors, monophyly constraints, and parameters for molecular clock models. We used Yule process as a tree prior and exponential distribution as a distribution prior for fossil calibration points, which is shown to be suitable for modelling fossil calibrations (Ho, 2007). The ML phylogram generated from RAxML was transformed into an ultrametric chronogram using non-parametric rate smoothing (NPRS) in TreeEdit (Rambaut and Charleston, 2001), and the base of the ingroup was re-scaled to the minimum age of the earliest definitive fossil Orthoptera (299 MYA) to scale the entire chronogram. This rescaled chronogram was utilized as a user-specified starting tree for the BEAST analyses. We placed monophyly constraints on nine nodes on the phylogeny based on the previous studies (Flook et al., 1999; Leavitt et al., 2013) as well as the ML analysis, and we selected the corresponding nine fossil calibration points from the literature (Brongniart, 1885; Scudder, 1885; Piton, 1940; Sharov, 1968; Riek, 1976; Bethoux et al., 2002; Heads and Leuzinger, 2011) and applied age constraints as priors (Table 3). To assess convergence across independent runs, we conducted two separate analyses each for 100 million generations, sampling every 1000 generations. We inspected the results using Tracer (Rambaut and Drummond, 2003-2009) and discarded 25\% of each run as burn-in, and combined the trees using LogCombiner (Rambaut and Drummond, 2002-2013a). A maximum clade credibility tree was summarized in TreeAnnotator (Rambaut and Drummond, 20022013b), and visualized in FigTree.

\section{Diversification analysis}

We used the program MEDUSA (Alfaro et al., 2009) in order to test whether certain lineages have given rise to clades with unusual species richness. We first reduced the total evidence ML phylogeny into a family-level tree by collapsing the nodes so that each terminal represented a single monophyletic family. We converted this reduced tree into a chronogram using the results from the divergence time estimate analysis. As for the species richness, we obtained the number of valid extant species in each family from the Orthoptera Species File (Eades et al., 2014) and the Mantodea Species File (Otte et al., 2014). We fitted a piecewise birth-death model to the chronogram and allowed the 
Table 3

Fossil calibration constraints used in the divergence time estimate analysis

\begin{tabular}{|c|c|c|c|c|c|}
\hline & & Species & $\begin{array}{l}\text { Median age }[\mathrm{MYA}] \\
\text { (minimum-maximum) }\end{array}$ & Notes & Reference \\
\hline \multicolumn{6}{|l|}{ ORTHOPTERA } \\
\hline Oedischioidea & Oedischiidae & Oedischia williamsoni & $301.45(299-303.9)$ & $\begin{array}{l}\text { Oldest definitive } \\
\text { Orthoptera }\end{array}$ & Brongniart (1885) \\
\hline \multicolumn{6}{|l|}{ ENSIFERA } \\
\hline \multirow[t]{2}{*}{ Grylloidea } & Raphoglidae & Raphogla rubra & $255.7(251-260.4)$ & Oldest definitive Ensifera & Bethoux et al. (2002) \\
\hline & Protogryllidae & Protogryllus & $231.5(228-235)$ & $\begin{array}{l}\text { Oldest definitive Grylloidea } \\
\text { (undescribed) }\end{array}$ & $\begin{array}{l}\text { Heads and Leuzinger } \\
\text { (2011) }\end{array}$ \\
\hline Tettigonioidea & Tettigoniidae & $\begin{array}{l}\text { Pseudotettigonia } \\
\text { amoena* }^{*}\end{array}$ & $57.0(54-60)^{*}$ & $\begin{array}{l}\text { Oldest definitive } \\
\text { Tettigoniidae }\end{array}$ & Zeuner $(1937)^{*}$ \\
\hline \multicolumn{6}{|l|}{ CAELIFERA } \\
\hline Locustopsoidea & Eolocustopsidae & Eolocustopsis primitiva & $255.7(251-260.4)$ & $\begin{array}{l}\text { Oldest definitive Caelifera } \\
\text { and Acridomorpha }\end{array}$ & Riek (1976) \\
\hline Tridactyloidea & Mongoloxyinae & $\begin{array}{l}\text { Monodactylus } \\
\text { curtipennis }\end{array}$ & $131.15(129.4-132.9)$ & $\begin{array}{l}\text { Oldest definitive } \\
\text { Tridactyloidea }\end{array}$ & Sharov (1968) \\
\hline Tetrigoidea & Tetrigidae & Prototetrix reductus & $131.15(129.4-132.9)$ & Oldest definitive Tetrigidae & Sharov (1968) \\
\hline Eumastacoidea & Eumastacidae & $\begin{array}{l}\text { Archaeomastax } \\
\text { jurassicus }\end{array}$ & $154.25(145-163.5)$ & $\begin{array}{l}\text { Oldest definitive } \\
\text { Eumastacoidea and } \\
\text { Eumastacidae }\end{array}$ & Sharov (1968) \\
\hline Acridoidea & Acrididae & Tyrbula russelli & $35.95(33.9-38)$ & $\begin{array}{l}\text { Oldest definitive } \\
\text { Acridoidea and Acrididae }\end{array}$ & Scudder (1885) \\
\hline
\end{tabular}

*[Corrections added after initial online publication on 9 March, 2015: the species (3rd column, 4th entry), 'Tettigonella chazei' updated as 'Pseudotettigonia amoena', Median age (4th column, 4th entry), '28.5 (23.1-33.9)' updated as '57.0 (54-60)' and Reference (6th column, 4th entry), 'Piton (1940) updated as 'Zeuner, (1937)' along with relevant update to the reference section.]

breakpoints to either be at the nodes or the stems. We used the sample size corrected Akaike information criterion $(\mathrm{AICc})$ to assess the models and the net diversification rate $(r)$ and relative extinction $(\varepsilon)$ were also estimated for each model.

\section{Results}

For the parsimony analysis of the complete mtgenome data (Fig. 4a), we found a single most parsimonious tree $(\mathrm{L}=130$ 483; $\mathrm{CI}=0.199 ; \mathrm{RI}=0.365)$. We failed to recover monophyly of Orthoptera as well as Stenopelmatoidea, Eumastacoidea, and Acridoidea, although we recovered monophyletic suborders. Nodal supports were generally poor across all backbone nodes. For the ML analysis of the same data (Fig. 4b), we recovered robust monophyly for Orthoptera as well as each suborder and all of the superfamilies except Stenopelmatoidea. The parsimony analysis of the total evidence data yielded three most parsimonious trees $(\mathrm{L}=148$ 589; $\mathrm{CI}=0.204$; $\mathrm{RI}=0.414)$. A strict consensus tree (not shown) recovered monophyly of Orthoptera, Ensifera, and Caelifera, as well as Schizodactyloidea, Grylloidea, Hagloidea, Rhaphidophoroidea, Tettigonioidea, Tridactyloidea, Tetrigoidea, Proscopioidea, and Eumastacoidea. However, it did not find Stenopelmatoidea, Pyrgomorphoidea, and Acridoidea as monophyletic, and had wildly different placements for Proscopioidea, Trigonopterygoidea, and Tanaoceroidea from previous phylogenetic studies of Caelifera (Flook and Rowell, 1997; Flook et al., 1999, 2000; Leavitt et al., 2013). The ML analysis of the total evidence data recovered monophyly of Orthoptera, both suborders, and all 15 superfamilies (Fig. 5). Because mtgenome data and nuclear rRNA genes of Orthoptera have been known to exhibit base compositional heterogeneity and variable substitution rates (Legendre et al., 2010; Sheffield et al., 2010; Song et al., 2010; Leavitt et al., 2013), the poor performance of the parsimony analyses was to be expected. Thus, the further comments on phylogenetic relationships are based on the ML analyses.

Within Ensifera, we recovered monophyly for five of six superfamilies in the mtgenome analysis, and all six superfamilies in the total evidence analysis. In the mtgenome analysis, Gryllacrididae did not form a clade with other members of Stenopelmatoidea, but in the total evidence analysis, Gryllacrididae, Stenopelmatidae, Anostostomatidae, and Cooloolidae formed a monophyletic group. Schizodactyloidea was found to be sister to Grylloidea in the mtgenome analysis, but it was placed basally to the non-grylloid ensiferans in the total evidence analysis. Within Grylloidea, two clades were consistently found, one consisting of Gryllidae, and the other consisting of Gryllotalpidae, Mogoplistidae, and Myrmecophilidae. In both analyses, Rhaphidophoroidea, Stenopelmatoidea, and Hagloidea formed a monophyletic group, which in turn was sister to Tettigonioidea. Within Caelifera, we recovered monophyly 
(a) Parsimony

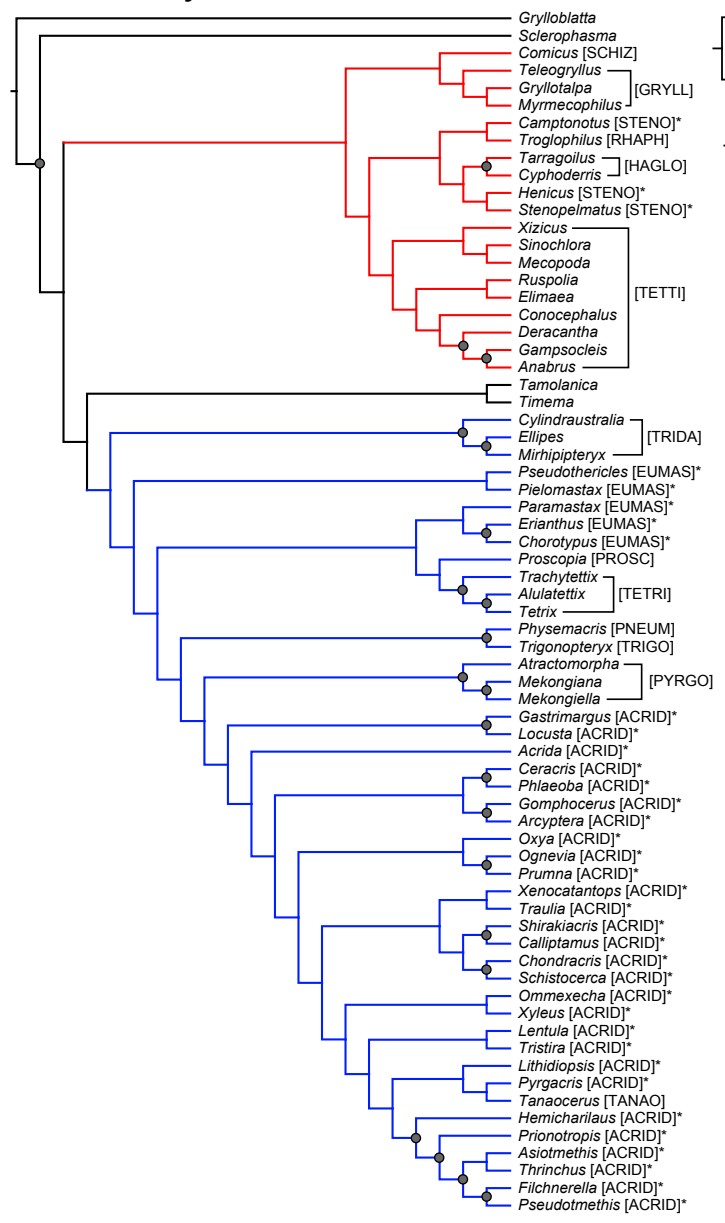

(b) Maximum likelihood

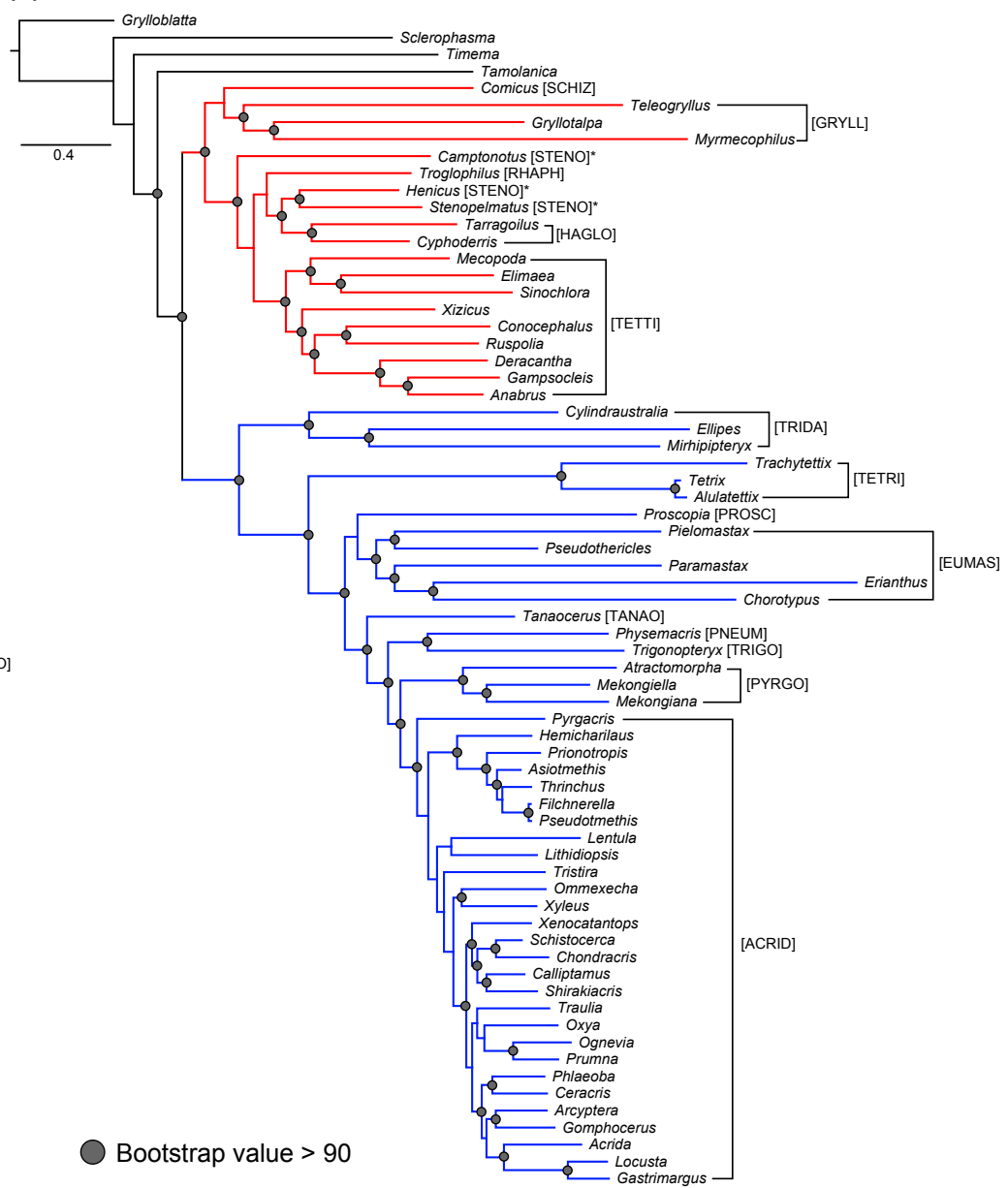

Fig. 4. Phylogenetic analyses based on complete mtgenome data. (a) The single most parsimonious tree from the parsimony analysis; (b) the most likelihood phylogram from the ML analysis. Branches are colour coded in red to indicate Ensifera and blue to indicate Caelifera. In the brackets are abbreviations of superfamily names. [SCHIZ]: Schizodactyloidea; [GRYLL]: Grylloidea; [STENO]: Stenopelmatoidea; [RHAPH]: Rhaphidophoroidea; [HAGLO]: Hagloidea; [TETTI]: Tettigonioidea; [TRIDA]: Tridactyloidea; [PROSC]: Proscopioidea; [EUMAS]: Eumastacoidea; [TANAO]: Tanaoceroidea; [PNEUM]: Pneumoroidea; [TRIGO]: Trigonopterygoidea; [PYRGO]: Pyrgomorphoidea; [ACRID]: Acridoidea. Asterisk denotes paraphyletic groups. Superfamily names used in this figure follow the currently recognized 15 superfamilies according to the Orthoptera Species File (Eades et al., 2014).

for all nine superfamilies with the following phylogenetic relationships: (Tridactyloidea (Tetrigoidea $(($ Proscopioidea + Eumastacoidea $) \quad$ (Tanaoceroidea ((Pneumoroidea + Trigonopterygoidea) (Pyrgomorphoidea + Acridoidea)))) ))). Within Acridoidea, Pyrgacrididae was the most basal lineage, followed by Pamphagodidae + Pamphagidae, Lentulidae + Lithidiidae, and Tristiridae. Ommexechidae showed a close relationship with Romaleidae in both analyses, but Romaleidae did not form a monophyletic group in the total evidence analysis. The monophyly of Acrididae was supported in the mtgenome analysis, but was not supported in the total evidence analysis due to paraphyly with Romaleidae.

When we compared our topology with the previous phylogenetic hypotheses using the $\mathrm{SH}$ and the AU test (Table 4), we found that the caeliferan relationship was not statistically different from that of Flook et al. (1999, 2000), but the ensiferan relationship was significantly different from both that of Desutter-Grandcolas (2003) and Jost and Shaw (2006). This pattern was found in both the mtgenome and the total evidence analyses. The topology deduced from the mtgenome data did not statistically differ from the total evidence topology.

The divergence time-estimate analysis based on nine fossil calibration points suggested that Orthoptera originated in the Carboniferous and the two suborders diverged in the Permian (Fig. 6). Within Ensifera, Grylloidea was the first lineage to diversify, starting in the Early Triassic and continuing throughout the Mesozoic. Other ensiferans diversified mostly in the Mesozoic and most of the major lineages within Tettigonioidea diversified in the Cretaceous. Caeliferan lineages showed different patterns of diversification and 


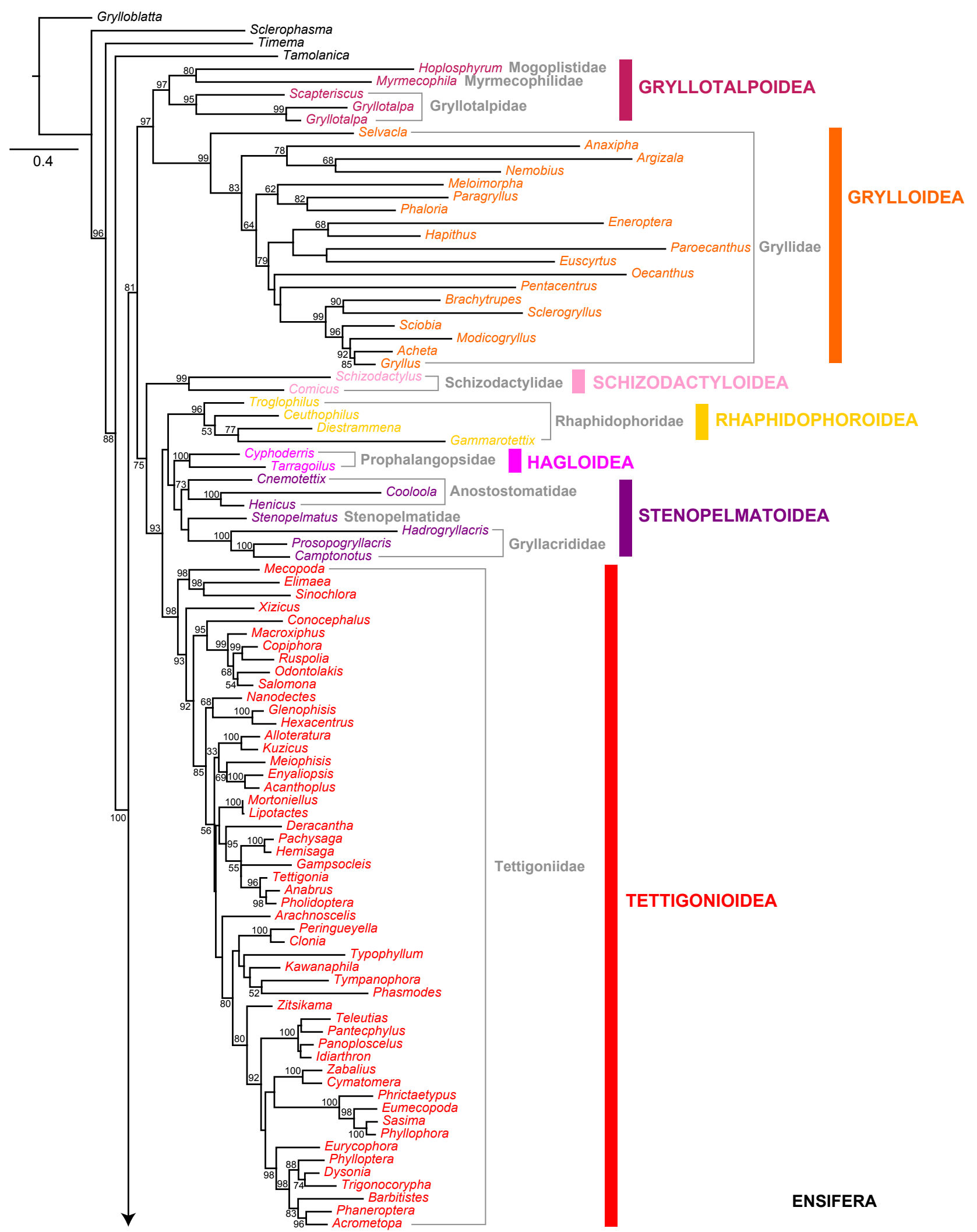

Fig. 5. Total evidence phylogeny of Orthoptera inferred from ML analysis. Numbers above the nodes are bootstrap support values. Asterisk denotes paraphyletic groups. Superfamily names used in this figure follow the proposed classification scheme in the present study. Thus, Gryllotalpoidea is indicated here as a distinct superfamily, separate from Grylloidea. 


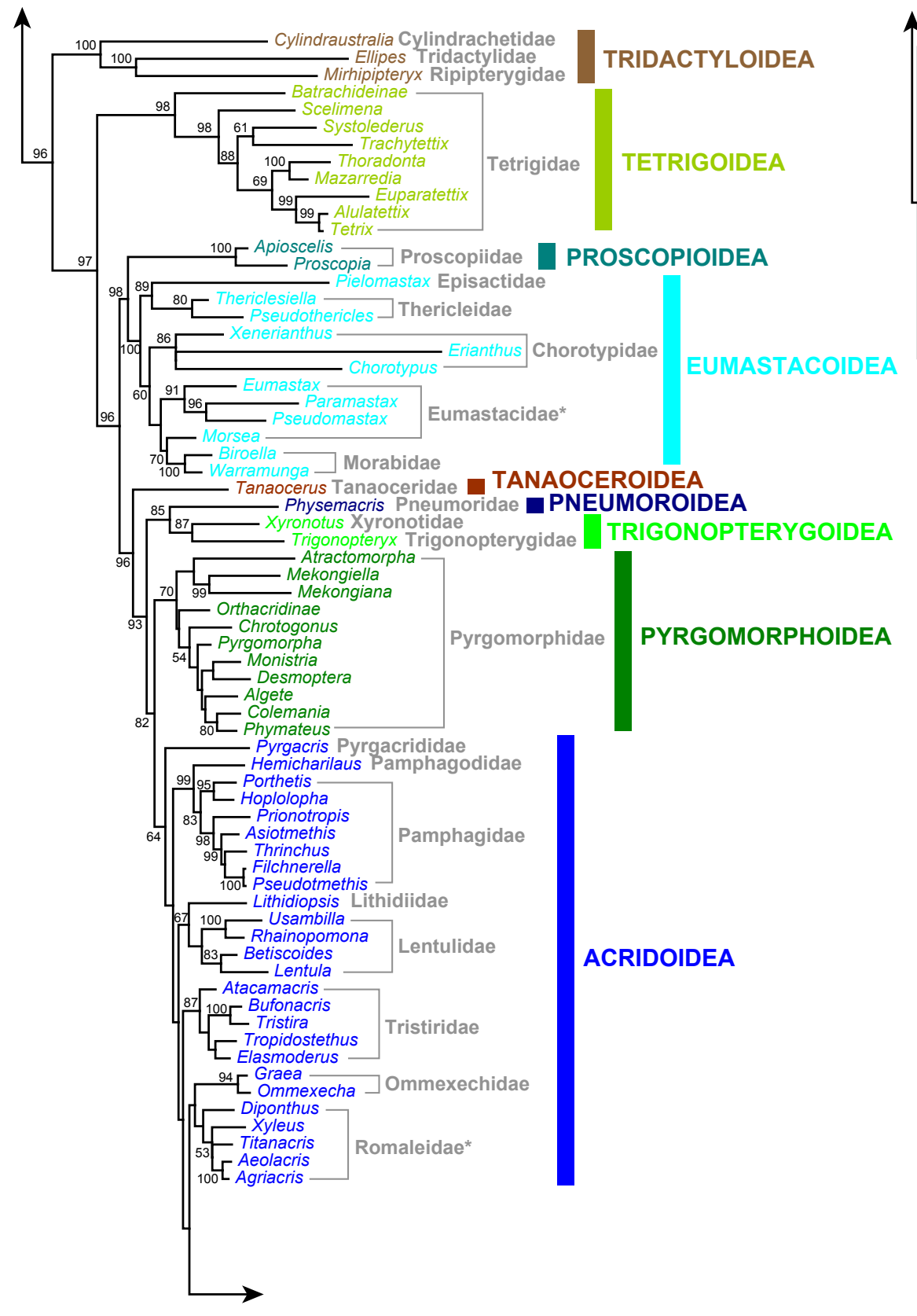

\section{CAELIFERA}

Fig. 5. (continued)

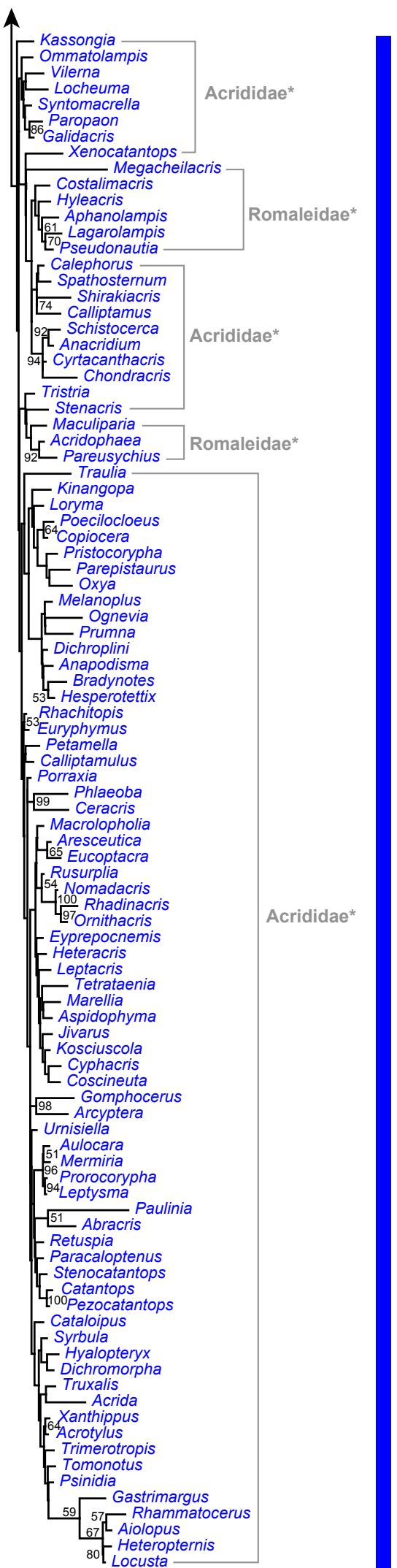


Table 4

Results of the Shimodaira-Hasegawa (SH) test and the approximately unbiased (AU) test against previous hypotheses

\begin{tabular}{|c|c|c|c|c|}
\hline Alternative hypothesis & Ln-likelihood score & SH test ( $P$-value $)$ & AU test ( $P$-value $)$ & Significantly different? \\
\hline $\begin{array}{l}\text { Caelifera relationship } \\
\text { sensu Flook et al. }(1999,2000)\end{array}$ & -491492.498 & 1.000 & 1.000 & No \\
\hline $\begin{array}{l}\text { Ensifera relationship } \\
\text { sensu Desutter-Grandcolas (2003) }\end{array}$ & -491668.521 & 0.000 & 0.000 & Yes \\
\hline $\begin{array}{l}\text { Ensifera relationship } \\
\text { sensu Jost and Shaw (2006) }\end{array}$ & -491771.721 & 0.000 & 0.000 & Yes \\
\hline $\begin{array}{l}\text { Caelifera relationship } \\
\text { sensu Flook et al. }(1999,2000)\end{array}$ & -588429.772 & 0.731 & 0.456 & No \\
\hline $\begin{array}{l}\text { Ensifera relationship } \\
\text { sensu Desutter-Grandcolas (2003) }\end{array}$ & -588908.165 & 0.000 & 0.000 & Yes \\
\hline $\begin{array}{l}\text { Ensifera relationship } \\
\text { sensu Jost and Shaw (2006) }\end{array}$ & -588812.682 & 0.000 & 0.000 & Yes \\
\hline
\end{tabular}

diverged into two groups that gave rise to two infraorders, Tridactylidea (Tridactyloidea) and Acrididea (the remaining eight superfamilies) in the late Palaeozoic. In the Late Triassic, Acrididea diverged into two lineages, Tetrigoidea and Acridomorpha, a monophyletic group characterized by grasshopper-like morphology that includes seven superfamilies (Dirsh, 1975; Song, 2010). Eumastacoidea and Proscopidoidea flourished in the Mesozoic and modern grasshoppers of the superfamily Acridoidea were the most recently diverged group, which diversified in the mid- to the Late Cretaceous. The major lineages of Acrididae seemed to have radiated in the Cenozoic.

Our MEDUSA analysis showed that the background tempo of diversification across Orthoptera was characterized by a relatively low net rate $(r=0.027$ lineages per Myr) and a moderate turnover rate $(\varepsilon=0.596)$. Using the number of validly described species as a proxy for clade-level diversity, we found that there were three episodes where the tempo of diversification significantly increased in Orthoptera (Fig. 7). The most significant change occurred in the clade consisting of Acrididae, Romaleidae, and Ommexechidae, which appeared to have gone through a major adaptive radiation with no major extinctions in the Cenozoic (node 1 in Fig. 7). The clade containing Tettigoniidae, Rhaphidophoridae, Prophalangopsiade, Anostostomatidae, Gryllacrididae, and Stenopelmatidae also went through an increased rate of diversification (node 2 in Fig. 7). Pamphagidae independently went through an increased rate of diversification (node 3 in Fig. 7). The third most diverse lineage in Orthoptera is Gryllidae, but our analysis did not find it to show any major shift in tempo of diversification, which suggests that the clade has continued to diversify throughout the evolutionary history of Orthoptera.

Finally, the gene arrangement in the mtgenome across Orthoptera was examined and we found that most ensif- eran lineages retained the ancestral gene arrangement, except two reported cases of gene rearrangements in Gryllidae and Tettigoniidae (Ye et al., 2008; Liu et al., 2013). We found an additional exception in a prophalangopsid Cyphoderris monstrosa, which had tRNA-Ala and tRNA-Arg reversed from the ancestral arrangement (Fig. 8). Within Caelifera, all three families of Tridactyloidea retained the ancestral condition, while the remaining caeliferan superfamilies had the tRNA genes between cytochrome $c$ oxidase subunit II (COII) and ATP synthase protein 8 (ATP8) rearranged so that tRNA-Asp was positioned before tRNA-Lys, which was reversed from the ancestral insect arrangement in which tRNA-Lys precedes tRNA-Asp. When this tRNA rearrangement was mapped onto the mtgenome phylogeny, we inferred that the rearrangement evolved in the common ancestor of Acrididea in the Late Permian or the Early Triassic (Fig. 6).

\section{Discussion}

\section{Towards a phylogeny-based natural classification} scheme for Orthoptera

This work represents the most comprehensive phylogenetic analysis of Orthoptera to date (Fig. 9) and presents an excellent opportunity to test previous hypotheses about the phylogenetic relationships among the major lineages within the order. Below, we comment on the higher-level relationships, which we can confidently resolve using the current data and we propose a new phylogeny-based natural classification scheme for Orthoptera (Table 5).

The phylogeny of Ensifera has been contentious over the years and numerous hypotheses have been proposed based on different character systems (Ander, 1939; Zeuner, 1939; Judd, 1947; Blackith and Blackith, 


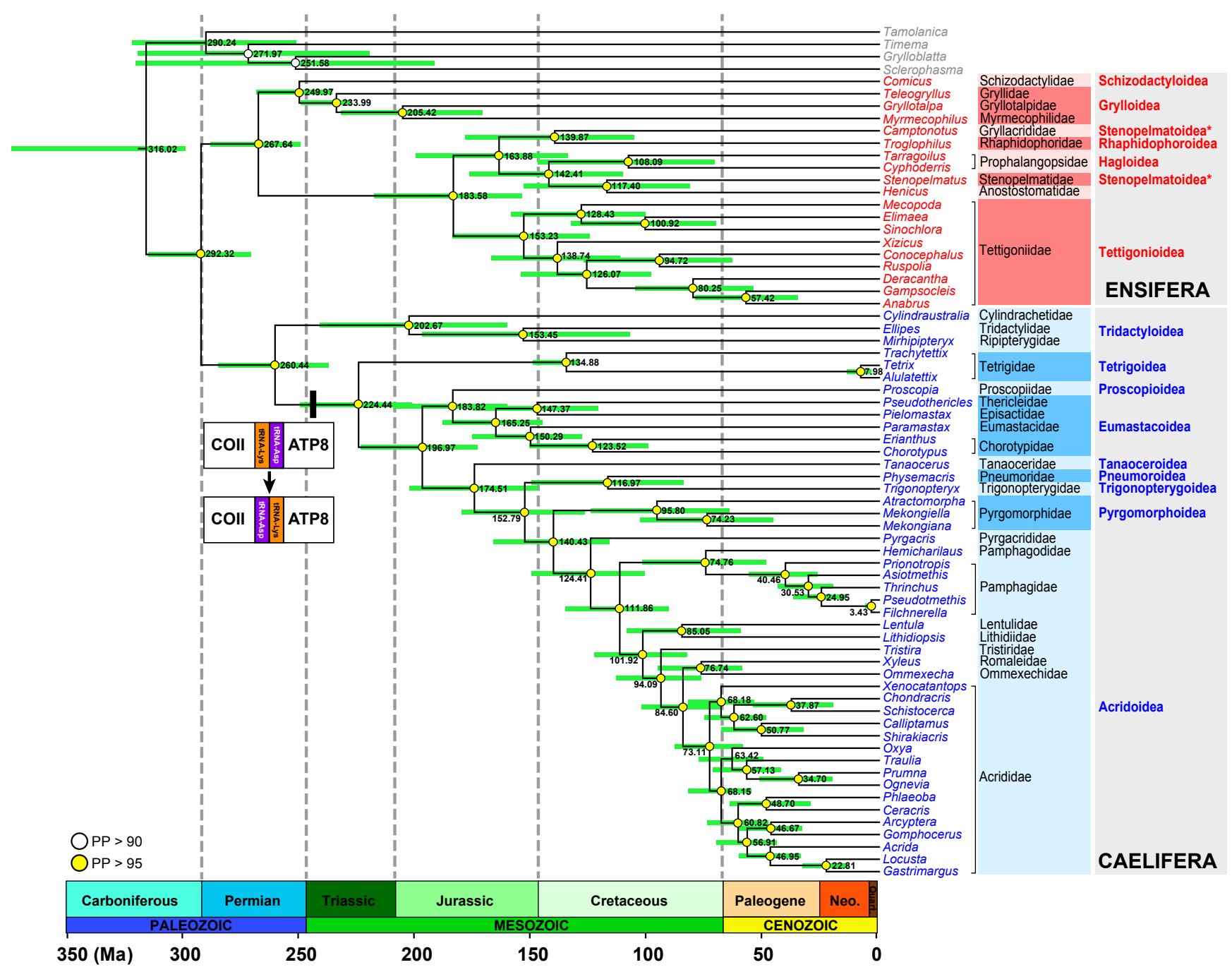

Fig. 6. A divergence time-estimate analysis of Orthoptera based on mtgenome data and nine fossil calibration points using BEAST. White and yellow circles on nodes indicate posterior probability values over 90 and 95 respectively. Green bars represent the node age $95 \%$ credible intervals and the numbers next to the nodes are the estimated node ages. Terminals are colour coded to show superfamily-level relationships. Superfamily names used in this figure follow the currently recognized 15 superfamilies according to the Orthoptera Species File (Eades et al., 2014). Asterisk denotes paraphyletic groups. Also shown is the evolution of tRNA gene rearrangement, which took place in the common ancestor of Tetrigoidea and Acridomorpha.

1968; Sharov, 1968; Ragge, 1977; Gorochov, 1995a; Gwynne, 1995; Desutter-Grandcolas, 2003; Jost and Shaw, 2006). Our total evidence phylogeny (Fig. 5) finds that Ensifera is mainly divided into two groups, one consisting of Grylloidea sensu Gorochov (1995b) and the other consisting of Schizodactyloidea sensu Kevan (1982), Hagloidea sensu Kevan (1982), Rhaphidophoroidea sensu Kevan (1982), Stenopelmatoidea sensu Kevan (1982), and Tettigonioidea sensu Kevan (1982). Although the internal relationships differ, this grouping is similar to the hypothesis proposed by Ander (1939) and corresponds to the infraorders Gryllidea sensu Vickery (1977) and Tettigoniidea sensu Vickery (1977). Within the infraorder Gryllidea, we have recovered Gryllidae (crickets) as sister to a clade con- sisting of Gryllotalpidae (mole crickets), Mogoplistidae (scaly crickets), and Myrmecophilidae (ant-loving crickets). The close relationship between Gryllidae and Gryllotalpidae has always been supported by previous studies (Ander, 1939; Zeuner, 1939; Judd, 1947; Sharov, 1968; Vickery, 1977), but their relationship with respect to the other two families has not been resolved because they have sometimes been included as subfamilies of Gryllidae (Rehn and Hebard, 1912). Our phylogeny strongly suggests that Mogoplistidae and Myrmecophilidae form a clade, which is in turn sister to Gryllotalpidae. The clade formed by these three families is quite divergent from Gryllidae. Furthermore, many lineages within Gryllidae are also very divergent from each other, reflecting the ancient age of 


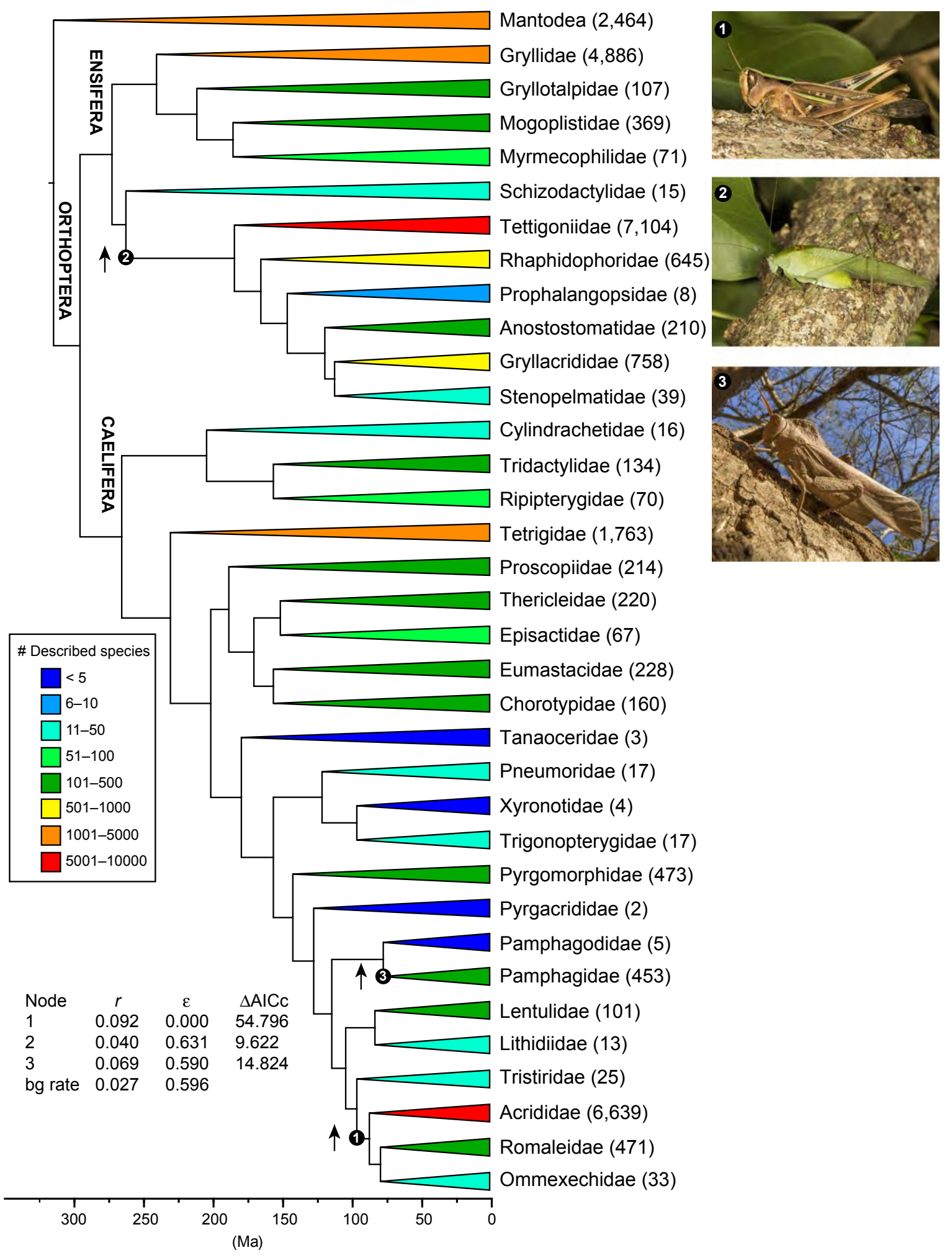

Fig. 7. Diversification patterns of major lineages of Orthoptera as deduced from MEDUSA analysis. Each terminal represents a monophyletic family and the number in parenthesis next to the family name indicates the number of validly described species within the family. Terminals are colour coded to show the species diversity. The MEDUSA analysis identified three episodes where diversification rate $(r)$ and extinction rate $(\varepsilon)$ significantly changed, which are indicated by black circles on nodes. The up arrows indicate an increase in diversification rates. The images on the right show the representatives of the clades that experienced the shifts in diversification rate. (Photograph credit: Hojun Song [1, 2], Piotr Naskrecki [3]) 
(a) Insect ancestor, Ensifera and Tridactyloidea

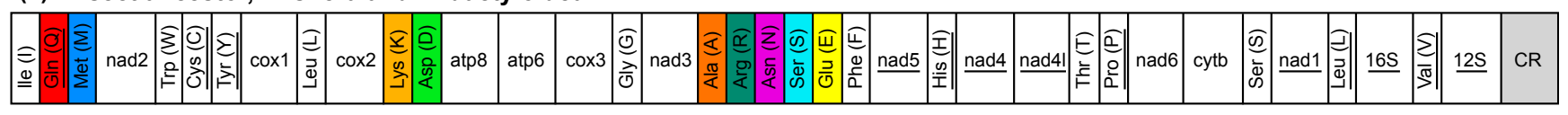

(b) Acrididea (Tetrigoidea and Acridomorpha)

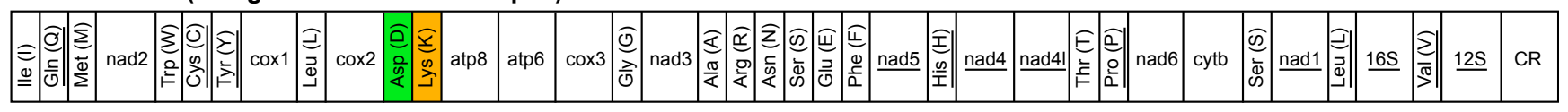

(c) Teleogryllus emma \& T. commodus

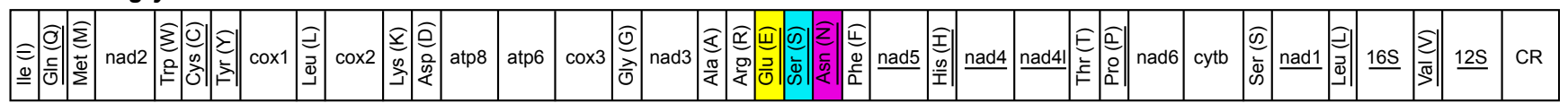

(d) Sinochlora longifissa \& S. retrolateralis

\begin{tabular}{|c|c|c|c|c|c|c|c|c|c|c|c|c|c|c|c|c|c|c|c|c|c|c|c|c|c|c|c|c|c|c|}
\hline 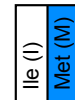 & nad2 & $C R$ & 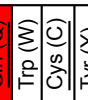 & & $\operatorname{cox} 1$ & 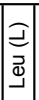 & $\cos 2$ & 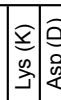 & atp8 & atp6 & $\cos 3$ & $\frac{\widehat{O}}{\frac{0}{3}}$ & $\operatorname{nad} 3$ & 3 & 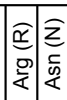 & 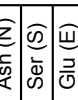 & 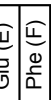 & nad5 & $\mid \begin{array}{l}\widehat{\underline{\underline{x}}} \\
\frac{\underline{\underline{x}}}{\bar{I}}\end{array}$ & $\mid$ nad4 & nad4 & 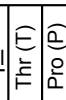 & nad6 & cytb & & nad1 & 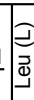 & $\underline{16 S}$ & $=\left|\frac{\sum}{\frac{\pi}{s}}\right|$ & $\underline{12 S}$ \\
\hline
\end{tabular}

(e) Cyphoderris monstrosa

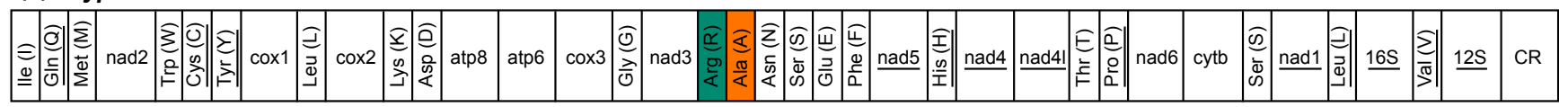

Fig. 8. Mitochondrial genome structures and known gene arrangements within Orthoptera. (a) Ancestral insect mtgenome structure, which is found in most ensiferans and Tridactyloidea; (b) tRNA rearrangement found in Acrididea, which is a molecular synapomorphy for the group; (c) Unique tRNA rearrangement found in Teleogryllus (Ye et al., 2008; Wolff et al., 2012); (d) Unique gene rearrangement found in Sinochlora (Liu et al., 2013); (e) Unique tRNA rearrangement found in Cyphoderris monstrosa.

the group, and it may be reasonable to elevate some of the gryllid subfamilies to the family level, given more thorough analyses with more taxon sampling in the future. In recognition of the two deeply divergent clades within Gryllidea, we propose recognition of two superfamilies within the infraorder, Grylloidea, which includes Gryllidae and Gryllotalpoidea, which includes the remaining three families. As our taxon sampling for Gryllidea is relatively weak compared with other groups included in this study, additional sampling may be necessary to test this hypothesis, but an independent analysis using a larger taxon sampling finds a similar relationship (Chintauan-Marquier et al., 2015), lending further support for this taxonomic change.

Within Tettigoniidea, we find a basal position of Schizodactyloidea, which comprises a small relict family Schizodactylidae (sand crickets), which is a novel hypothesis. The phylogenetic position of Schizodactyloidea within Ensifera has not been clear (Heads and Leuzinger, 2011). Jost and Shaw (2006), Legendre et al. (2010), as well as our mtgenome analysis, found it to be sister to Gryllidea, while other morphologybased studies placed them near Tettigoniidea (Ander, 1939; Gorochov, 1995a; Desutter-Grandcolas, 2003). Heads and Leuzinger (2011) supported a sister relationship between Schizodactyloidea and Gryllidea, which was first proposed by Gwynne (1995), but it was not based on a formal cladistic analysis. Upon close examination of our data, we find that the branch lengths of the members of Gryllidea are exceptionally long and it is possible that our mtgenome analysis may have been affected by long-branch attraction (Felsenstein, 1978; Bergsten, 2005), meaning that the resulting topology may be an analytical artefact, rather than an accurate relationship. The larger taxon and character sampling of the total evidence analysis seems to have overcome this issue.

We then recover a sister relationship between Tettigonioidea and the remaining three monophyletic superfamilies (Hagloidea, Rhaphidophoroidea, and Stenopelmatoidea). Many of the earlier taxonomists have considered Tettigonioidea and Hagloidea to be closely related because these are the only two superfamilies outside Gryllidea that emit sounds with a tegminal design and hear with tibial tympanal structures (Ander, 1939; Zeuner, 1939; Ragge, 1955; Gwynne, 1995; Desutter-Grandcolas, 2003). However, it is important to recognize that many ensiferans within Tettigoniidea can also produce femoro-abdominal stridulation, which can be perceived by either membranous tympana or mechanoreceptors (Desutter-Grandcolas, 2003). Tettigonioidea includes the most diverse and speciose orthopteran family, Tettigoniidae (katydids), which has the stridulatory file on the left tegmen (Gwynne, 2001), and Hagloidea, which includes only a 
Table 5

A phylogeny-based natural classification scheme proposed in this study

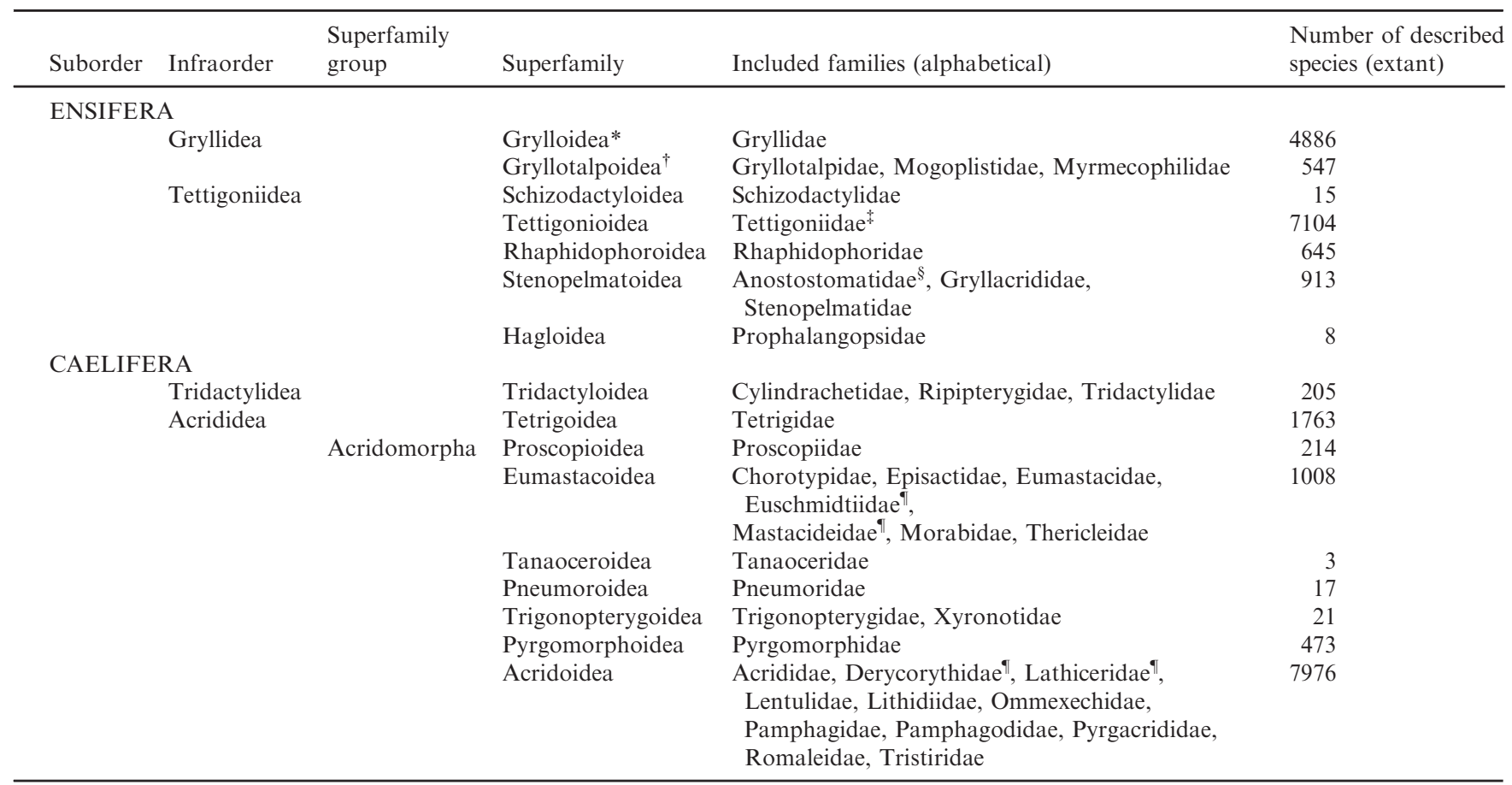

* Grylloidea used to be the sole superfamily within Gryllidea. Now we recognize it as containing a single family Gryllidae. Upon further studies in the future, Gryllidae may be divided into more families.

${ }^{\dagger}$ Here, we recognize the superfamily Gryllotalpoidea as a distinct lineage from Grylloidea to include Gryllotalpidae, Mogoplistidae, and Myrmecophilidae based on our phylogenetic analyses.

"In this study, we recognize a single family Tettigoniidae, which includes Phaneropteridae sensu Heller et al. (2014). The katydid classification is clearly in a state of flux and a major revision of the classification will be required with more data in the future.

${ }^{\S}$ We consider Cooloolidae as an aberrant member of Anostostomatidae and do not recognize it as a valid family.

"These four families are not included in this study.

single extant family, Prophalangopsidae (ambidextrous crickets), and numerous extinct families, all of which have stridulatory files on both tegmina (Spooner, 1973). Jost and Shaw (2006) proposed a more radical scheme, which placed Hagloidea (represented by Cyphoderris only) as the most basal lineage within Ensifera and suggested that acoustic communication is the ancestral condition for Ensifera and has been lost multiple times. Recently, Zhou et al. (2014) suggested a sister relationship between Hagloidea and Rhaphidophoroidea based on mtgenome data, but the study lacked robust taxon sampling because it included only one species per superfamily and did not include the members of Stenopelmatoidea. Our study finds a novel relationship and does not find support for the sister relationship between Tettigonioidea and Hagloidea, or the sister relationship between Hagloidea and Rhaphidophoroidea, or the basal placement of Hagloidea. Instead, we find the clade (Rhaphidophoroidea (Hagloidea + Stenoplematoidea)), which is, in turn, sister to Tettigoniidae. The acoustic communication is certainly a very complex syndrome that can be achieved from diverse ways of producing sound and equally diverse ways of perceiving sound (Desutter-Grandcolas, 2003) and it is not well justified to treat it as a simple binary character to test whether it is ancestral or derived. A more appropriate way is to conduct a detailed anatomical study to carefully form homology statements of various components of sound production and hearing to optimize on to the phylogeny. Thus, a study with larger taxon sampling and detailed morphological analyses is necessary to fully understand the evolution of acoustic communication in these insects.

Recently, Heller et al. (2014) elevated the status for the tettigoniid subfamily Phaneropterinae to full family Phaneropteridae, which includes four plant-feeding subfamilies, Phaneropterinae, Pseudophyllinae, Mecopodinae, and Phyllophorinae, based on a recent molecular study by Mugleston et al. (2013) and a previous hypothesis by Gorochov (1995b). This taxonomic change implies that Phaneropteridae as a whole is a monophyletic group, but Mugleston et al. (2013) found that one of the pseudophylline tribes, Pterochrozini, did not group with other pseudophyllines, but was placed at the base of katydid phylog- 


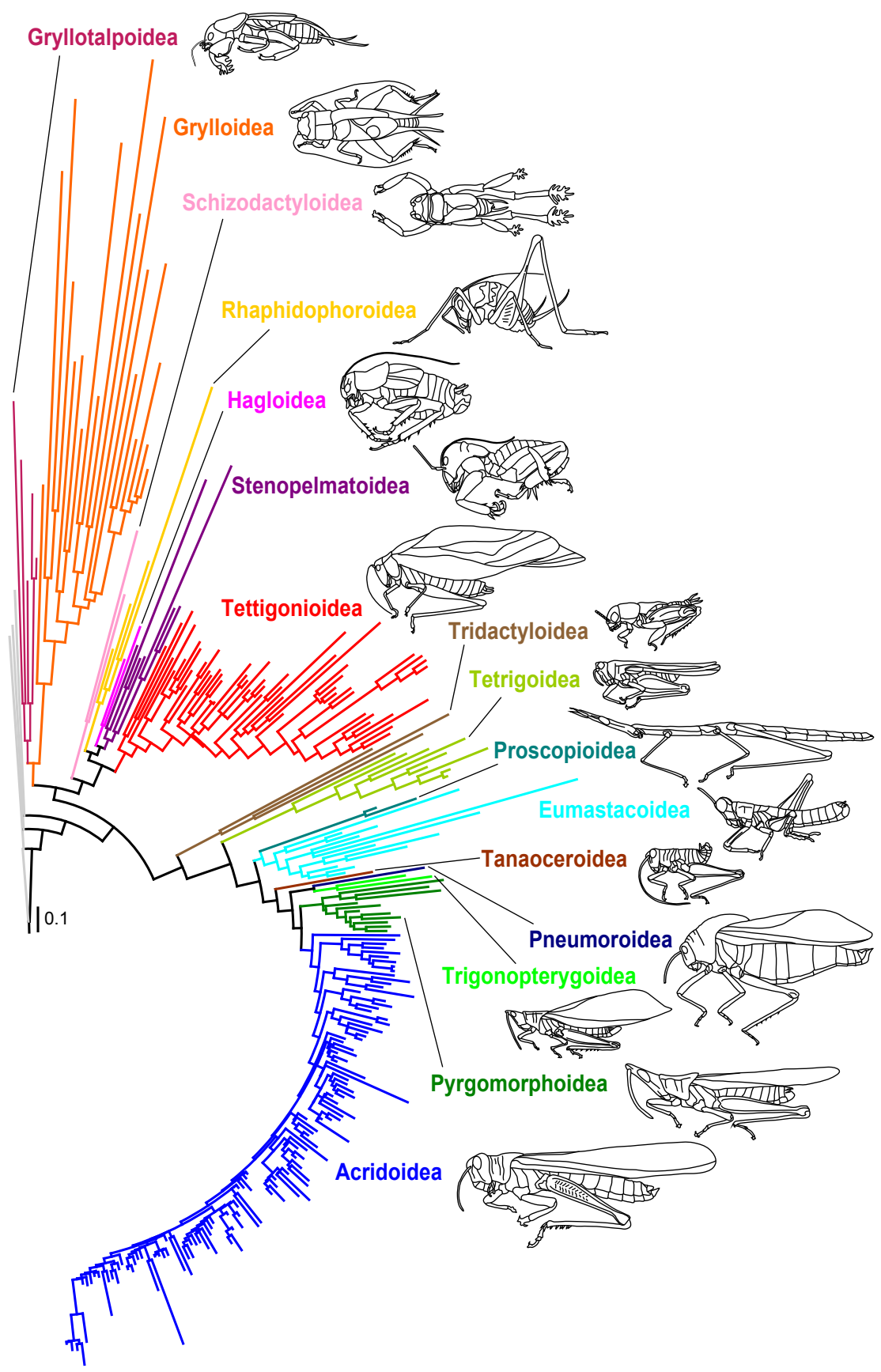

Fig. 9. A summary phylogeny of Orthoptera based on ML analysis of total evidence data. For readability, terminals are not shown, but branches are colour coded to show their superfamily identity. Superfamily names used in this figure follow the proposed classification scheme in the present study.

eny, thereby rendering the concept of Phaneropteridae paraphyletic. Our study is built upon the data generated by Mugleston et al. (2013), and we also do not find strong support for the family Phaneropteridae. To make matters worse, Gorochov (2012) elevated several tribes within Pseudophyllinae to subfamilies and created a "subfamily group" Pseudophyllidae, but this hypothesis has not been fully tested. The katydid classification is clearly in a state of flux and a major revision of the classification will be required once a definitive phylogeny of Tettigoniidae becomes available. Thus, in this study, we recognize a single family, Tettigoniidae, that has always been found monophyletic.

Our study proposes a novel phylogenetic position for Rhaphidophoroidea, which includes a single cosmopolitan family Rhaphidophoridae (camel crickets). 
Gorochov (2001) considered Rhaphidophoridae as a member of Stenopelmatoidea, but our study shows that it is divergent from Stenopelmatoidea. Likewise, a sister relationship between Stenopelmatoidea and Hagloidea is also novel. Although our analysis based on the mtgenome finds only paraphyletic Stenopelmatoidea, the total evidence analysis (Fig. 5) based on more taxon sampling strongly recovers the monophyly of the superfamily consisting of Anostostomatidae (wetas and king crickets), Stenopelmatidae (Jerusalem crickets), and Gryllacrididae (raspy crickets and leaf-rolling crickets). Anostostomatidae is found to be paraphyletic with respect to Cooloolidae (cooloola monsters), but evidence suggests that Cooloolidae are actually aberrant Anostostomatidae, and Gorochov (2001) also expressed this view. However, more taxon sampling is required to fully resolve the relationships among Rhaphidophoroidea, Stenopelmatoidea, and Hagloidea, and allow the definition of monophyletic units of evolution for extant taxa and fossils.

We now have a very clear understanding of the phylogeny of Caelifera and the relationships among superfamilies. Like Ensifera, Caelifera is mainly divided into two infraorders, Tridactylidea sensu Kevan (1982), which comprises a single superfamily, Tridactyloidea, and Acrididea sensu Kevan (1982), which includes all the other caeliferan superfamilies (Fig. 5). Previous molecular phylogenetic hypotheses of Caelifera (Flook and Rowell, 1997; Flook et al., 1999; Leavitt et al., 2013; Zhang et al., 2013a,b) consistently recovered the basal position of Tridactyloidea sensu Dirsh (1975), followed by Tetrigoidea sensu Dirsh (1975), and our study also confirms this hypothesis. Although some earlier studies focusing on the fossil evidence proposed a sister relationship between Tridactyloidea and Tetrigoidea (Ragge, 1955; Sharov, 1968), other morphologists thought that Tetrigoidea was more closely related to other caeliferan superfamilies (Dirsh, 1975; Kevan, 1982; Vickery, 1997) and our study concurs with the latter. Tridactyloidea is the earliest branch within Caelifera, currently consisting of three families, Tridactylidae (pygmy mole crickets), the Neotropical relative Ripipterygidae, and the subterranean Cylindrachetidae (sandgropers). Although Vickery (1997) considered Cylindrachetidae to form its own superfamily, Cylindrachaetoidea, Flook and Rowell (1997) included it within Tridactyloidea and our findings support this position. The infraorder Acrididea consists of Tetrigoidea and Acridomorpha, the former comprised of a single cosmopolitan family, Tetrigidae (pygmy grasshoppers and grouse locusts), which is characterized by the extension of the pronotum over the entire dorsal surface of the abdomen (Kevan, 1982). The latter is a group of seven superfamilies collectively known as Acridomorpha for their grasshopper-like morphology and herbivorous feeding habit (Dirsh, 1975; Flook and Rowell, 1997;
Song, 2010). The higher-level classification within Acridomorpha has been largely informed by male phallic structures (Dirsh, 1973; Amédégnato, 1974; Eades, 2000; Song, 2010), but individual taxonomists have interpreted these morphological characters differently from each other, resulting in several conflicting schemes (Song, 2010). Molecular data have been very useful in resolving these conflicts (Flook and Rowell, 1997; Flook et al., 1999, 2000; Leavitt et al., 2013). Recently, Song and Mariño-Pérez (2013) compared the phylogenetic signal in male phallic structures with that of molecular data, and showed that many traditionally used characters are highly homoplasious, while some phallic structures do have a strong signal. The present study is largely congruent with the previous molecular studies (Flook and Rowell, 1997; Flook et al., 1999, 2000; Leavitt et al., 2013) and clarifies some of the conflicts from the earlier taxonomic work.

In this study, we find that Acridomorpha is divided into two groups: Proscopioidea sensu Descamps $(1973 b)+$ Eumastacoidea sensu Descamps (1973b) and the clade consisting of the remaining five superfamilies. Proscopioidea comprises a single family Proscopiidae (jumping sticks). Although this phasmid-looking grasshopper family has sometimes been considered a member of Eumastacoidea (Dirsh, 1961, 1975), we consider it here as a separate superfamily based on its unique apomorphies (Descamps, 1973a,b) as well as its robust basal position relative to other eumastacoids. Our study clarifies the ambiguous position of Proscopioidea as found by Matt et al. (2008). Eumastacoidea includes seven families (Eades et al., 2014) that are commonly referred to as monkey grasshoppers. Of the remaining five superfamilies within Acridomorpha, the earliest diverging lineage is Tanaoceroidea sensu Kevan (1982), which includes a small relict family Tanaoceridae, known only from three species endemic to the southwestern USA, and characterized by extremely long antennae and a rudimentary male phallic complex (Rehn, 1948; Dirsh, 1955; Grant and Rentz, 1967).

Then the lineage is divided into two clades, one consisting of Pneumoroidea sensu Flook et al. (2000) and Trigonopterygoidea sensu Flook et al. (2000) and the other consisting of Pyrgomorphoidea sensu Flook et al. (1999) and Acridoidea sensu Flook et al. (2000). Pneumoroidea contains one family, Pneumoridae (bladder grasshoppers, flying gooseberries), and 17 described species mostly found in South Africa, and is known for its femoro-abdominal stridulatory mechanism (Dirsh, 1965). Trigonopterygoidea consists of two rather divergent families, Trigonopterygidae and Xyronotidae. The former is endemic to Southeast Asia, contains 17 species, and is characterized by reversed male genitalia and foliaceous tegmina (Dirsh, 1952). The latter contains four species endemic to central Mexico and can be characterized by rudimentary 
male genitalia and a stridulatory ridge on the third abdominal tergite (Dirsh and Mason, 1979). Flook et al. (2000) recovered these two families as a monophyletic group and our study corroborates their findings. However, the sister relationship between Pneumoroidea and Trigonopterygoidea is novel. Dirsh and Mason (1979) considered Tanaoceridae, Pneumoridae, and Xyronotidae to form a monophyletic lineage because of the apparently shared femoro-abdominal stridulatory mechanism, but Flook et al. (2000) thoroughly showed that this morphological trait must have evolved multiple times within the basal caeliferans and our findings bolster this idea.

Pyrgomorphoidea includes a single family, Pyrgomorphidae (gaudy grasshoppers), that contains about 470 species distributed globally, with most of its diversity found in the Old World, and is characterized by the presence of a groove in the fastigium (Kevan and Akbar, 1964). Members of this family are often large, strikingly coloured, and known to feed on toxic plants for their defense (Rowell, 1967; Chapman et al., 1986; Whitman, 1991). Dirsh (1975) placed the family Pamphagidae within Pyrgomorphoidea based on the similarity of male phallic structures, but our study clearly shows that Pyrgomorphidae alone forms a distinct sister lineage to Acridoidea, and Pamphagidae is firmly included within Acridoidea, which corroborates the earlier findings by Flook and Rowell (1997) and Flook et al. (1999).

Finally, Acridoidea is the largest superfamily within Acridomorpha, and currently includes 11 recognized families and more than 7900 described species, which are defined by the morphology of the male phallic complex and the lack of a basioccipital slit, among other characters (Roberts, 1941; Chopard, 1949; Dirsh, 1973; Amédégnato, 1974; Kevan, 1982; Eades, 2000). Many species in this group can be recognized as typical and familiar grasshoppers. Within Acridoidea, we find that Pyrgacrididae, which is endemic to Réunion Island in the Indian Ocean (Hugel, 2005), is the earliest diverging lineage, representing a transitional form between Pyrgomorphoidea and Acridoidea (Eades, 2000). Leavitt et al. (2013) found Pamphagidae + Pamphagodidae to be the basal lineage within Acridoidea, but their nodal support for the backbone relationships was poor. The present study is based on large taxon and character sampling and our nodal support is much stronger than that of Leavitt et al. (2013).

\section{Divergence and diversification patterns of major orthopteran lineages}

Orthoptera has evolved over $300 \mathrm{Myr}$ (Sharov, 1968; Gorochov, 1995a; Storozhenko, 1997; Grimaldi and Engel, 2005) and its current diversity has been shaped by dynamic shifts of diversification rates at different geological times across different lineages within the order. Some clades are very diverse and show a cosmopolitan distribution, while others are represented by only a small number of species and have a very limited geographical distribution (Kevan, 1982). Moreover, different clades show characteristic morphological, ecological, and behavioral traits, which appear to be phylogenetically conserved within each lineage (Kevan, 1982). Using the divergence time estimates (Fig. 6) and the MEDUSA analysis (Fig. 7), we have revealed some interesting patterns of diversification, and here we comment on the evolution of the three most diverse and cosmopolitan orthopteran clades, crickets (Grylloidea), katydids (Tettigoniidae), and grasshoppers (Acrididae), to highlight the complexity of orthopteran evolution.

Crickets represent one of the most ancient lineages within Orthoptera and we estimate that they diverged from other groups probably in the Triassic. They form the third most diverse clade with more than 4800 known species (Eades, 2000) and our MEDUSA analysis shows that they did not experience any major shifts in diversification rates, implying that the lineage has continued to diversify since the origin of the clade (Fig. 7). However, this result needs to be interpreted cautiously because it is possible that different patterns might emerge if the whole diversity of Grylloidea indeed consists of multiple valid families (Chopard, 1949). Modern crickets are mostly nocturnal, brown or black in colour, and omnivorous scavengers (Alexander, 1968), and these ecological characters could have originated in the early Mesozoic. What sets the crickets apart from other ancient insects of similar ecological habits is their ability to communicate acoustically (Greenfield, 1997), even if the loss of acoustic communication is frequent in crickets, contrary to tettigoniids. Cricket songs are mainly used in the context of intraspecific sexual behaviour (Otte, 1992; Greenfield, 1997), which suggests that acoustic crickets are under sexual selection. Many closely related species can be diagnosed by their male calling songs. Sexually selected characters tend to evolve rapidly (Lande, 1981; West-Eberhard, 1983) and, in fact, sexual selection on male calling songs has been postulated as a likely reason for the extremely rapid speciation in a Hawaiian genus, Laupala (Mendelson and Shaw, 2005). At the same time, these songs can attract predators and parasitoids, which can provide strong selective pressure for the crickets to evolve silence rapidly (Pascoal et al., 2014), or modify their signals into less conspicuous ones, such as the ultrasounds used by Eneopterinae (Robillard et al., 2007). Therefore, it is conceivable that both sexual selection on songs and natural selection may have played an important role for cricket diversification over the past $200 \mathrm{Myr}$, which may have contributed to the current diversity. 
Katydids represent the most successful lineage within Orthoptera in terms of species diversity (Eades, 2000). They are also very diverse in terms of ecological traits, with their diets ranging from herbivory to carnivory, and they can be active during both the day and night (Gwynne, 2001). Like crickets, katydids communicate acoustically, with their songs ranging from audible sound to ultrasound (Greenfield, 1997; Gwynne, 2001; Montealegre-Z, 2009), with very rare loss of acoustic communication, and sexual selection has likely played an important role in their diversification. Although definitive fossils of Tettigoniidae are only known from the Cenozoic (Piton, 1940; Sharov, 1968; Gorochov, 1995b; Storozhenko, 1997), our divergence time-estimate analysis suggests that the family probably originated in the Late Jurassic and diversified into major lineages in the Cretaceous (Grimaldi and Engel, 2005). Furthermore, the MEDUSA analysis suggests that there was an increase in diversification rate in the lineage leading to this clade (Fig. 7). This period coincides with the diversification of angiosperms (Soltis et al., 2005) and complex palaeoclimatic patterns (Bender, 2013). Many modern katydids have tegmina resembling angiosperm leaves, which function as a defense mechanism against visual predators via crypsis or mimesis (Nickle and Castner, 1995), and a recent molecular phylogeny of Tettigoniidae (Mugleston et al., 2013) showed that leaf-like wings have evolved multiple times within the family. Among the herbivorous katydids, the diet habits vary across florivory, granivory, and folivory (Gwynne, 2001), which suggests that the availability of diverse angiosperms could have promoted the diversification of katydids. Although katydids appear to show a cosmopolitan distribution, only three groups, Conocephalinae, Phaneropterinae, and Pseudophyllinae, are truly cosmopolitan, while the other lineages have more restricted distributions (Kevan, 1982; Eades et al., 2014). This suggests that the numerous vicariance events that followed the break-up first of Pangaea, and later of Gondwana and Laurasia, may have played an important role in the divergence of major katydid lineages. This biogeographical pattern also seems to explain the distribution of crickets.

Grasshoppers represent the most recently diverged lineage within Orthoptera. Fossil acridids are frustratingly scarce and most of the known fossils are from the mid- to late Cenozoic (Sharov, 1968; Storozhenko, 1997; Grimaldi and Engel, 2005). We estimate that the ancestral Acrididae probably originated in the Late Cretaceous, but it is likely that the major diversification events happened after the Cretaceous-Paleogene (K-Pg) boundary, well into the Cenozoic. The MEDUSA analysis identifies the lineage leading up to Acrididae to have undergone a significant increase in diversification rate with little or no extinction (Fig. 7).
During the Cenozoic, global climate generally became temperate (Bender, 2013), and grasses evolved and became dominant (Strömberg, 2011). Grasshoppers are exclusively herbivores and many lineages have adapted to graminivory (Uvarov, 1977). They are among the dominant herbivores of grasslands and rangelands, known to consume nearly $10 \%$ of plant biomass in such habitats (Gangwere et al., 1997). The most speciose acridid subfamily is Gomphocerinae (Eades et al., 2014), which has its mouthparts adapted for graminivory (Isley, 1944). Thus, it is conceivable that the diversification of grasses, and particularly the spread of open grasslands (Dixon et al., 2014), could have played an important role in the diversification of grasshoppers. By the Cenozoic, the continents had approached their present-day configuration and large oceanic barriers existed between them. Many grasshopper lineages are known to be strong fliers and colonizers, and an extreme example of their flight can be illustrated from locust swarms that can migrate long distances, often across continents (Pener and Simpson, 2009). This suggests a possibility that at least some of the current cosmopolitan distribution of Acrididae could have been due to dispersal events. Our total evidence phylogeny (Figs 5 and 9) shows that the branch lengths for taxa belonging to Acrididae are extremely short, suggesting that only few changes have accumulated in the nuclear genes we have used amongst grasshoppers. From another angle, this pattern highlights a possibility that Acrididae may have undergone an explosive adaptive radiation, powered by the evolution of a new niche space (grasslands) and frequent founder events after the colonization of new habitats.

\section{Mitochondrial genome evolution}

A typical metazoan mtgenome consists of 37 genes (13 protein-coding, two ribosomal RNAs and 22 transfer RNAs) and a variable size of AT-rich control region (Clary and Wolstenhome, 1985; Boore, 1999), and has been shown to accurately resolve phylogenetic relationships over broad evolutionary periods across many insect groups (Cameron, 2014b). In this study, we show that the mtgenome data are very useful in resolving the phylogeny of Orthoptera. We also demonstrate that not only the sequence data of the mtgenome, but also its gene arrangements, contain important phylogenetic information. Flook et al. (1995) sequenced the first orthopteran mtgenome from the migratory locust, Locusta migratoria, and noticed that two tRNA genes (tRNA-Lys and tRNA-Asp) between COII and ATP8 were reversed from the ancestral insect arrangement. Subsequently, this tRNA rearrangement has been reported from other caeliferans, but not in any of the ensiferans (Flook and Rowell, 1995; Fenn et al., 2008; Sheffield et al., 2010). 
Leavitt et al. (2013) recently showed that Tridactylidae was the only caeliferan that did not have the rearrangement, thus retaining the ancestral condition. In this study, we show that all of the ensiferan superfamilies as well as all three families (Tridactylidae, Ripipterygidae, and Cylindrachetidae) of the basal caeliferan superfamily Tridactyloidea retain the ancestral gene arrangement (Fig. 8).

There are three exceptions, however. Ye et al. (2008) showed that the tRNA gene cluster tRNA-AsntRNA-Ser(AGN)-tRNA-Glu was inversely located in the minor strand in the cricket Teleogryllus emma, and Wolff et al. (2012) also showed that the congeneric $T$. commodus had the same gene rearrangement. It is not clear if other gryllids have this rearrangement. Additionally, Liu et al. (2013) found a novel gene order, 12S rRNA-tRNA-Ile-tRNA-Met-nad2-control region-tRNA-Gln-tRNA-Trp, in two katydid species in the genus Sinochlora, which was uniquely different from the ancestral order of $12 \mathrm{~S}$ rRNA-control regiontRNA-Ile-tRNA-Gln-tRNA-Met-nad2-tRNA-Trp.

Interestingly, none of the other Tettigoniidae mtgenomes shows this rearrangement, which suggests that this is an isolated incidence. In the present study, we also find that Cyphoderris monstrosa has tRNA-ArgtRNA-Ala, instead of the ancestral tRNA-Ala-tRNAArg, but this appears to be an isolated case because another prophalangopsid, Tarragoilus diuturnus, is not known to have any rearrangement (Zhou et al., 2014).

The only consistent tRNA gene rearrangement across the phylogeny is the one between COII and ATP8 and when this gene arrangement is mapped onto the phylogeny (Fig. 6), we find that it evolved in the common ancestor of Acrididea (Tetrigoidea + Acridomorpha). This suggests that this rearrangement has persisted for nearly $250 \mathrm{Myr}$ since this lineage diverged from Tridactylidea. Thus, this gene rearrangement can be considered a clear molecular synapomorphy for Acrididea. Mitochondrial gene rearrangements have been frequently reported in Paraneoptera and Holometabola (Cameron, 2014b), but so far Orthoptera is the only polyneopteran lineage that shows this pattern and it appears to have happened infrequently. This pattern implies that such gene rearrangements must have been a rare event among polyneopteran insects.

\section{Future directions and challenges}

The present study represents a major milestone for orthopteran systematics and provides a framework for a phylogeny-based natural classification system for Orthoptera (Table 5). While this study has clarified many long-standing issues, it has also identified several areas of research that need further investigations. The first area is the relationship among basal ensiferans. Given the diversity of Rhaphido- phoroidea and Stenopelmatoidea, our taxon sampling in these groups is too sparse and these are also among the least studied groups within Orthoptera. Similarly, more sampling for Gryllidea is required to formally test the validity of Gryllotalpoidea and the relationships among the families, and check the definition of monophyletic families within Grylloidea. The second area is to thoroughly re-evaluate the classification of Tettigoniidae, specifically to address the recent taxonomic issue regarding the status of Phaneropteridae. The third area is the phylogeny of Tetrigoidea, which is one of the more ancient lineages and the second most speciose superfamily within Caelifera. Tetrigoidea has a cosmopolitan distribution and shows exceptional diversity in pronotum morphology. Nevertheless, a phylogeny of Tetrigoidea is completely unknown at this time. The last area is the phylogeny of Acrididae and Romaleidae. Our current data are unable to resolve the majority of the relationships within these families, mainly because the markers that we have used are too conserved and because grasshoppers appear to have undergone explosive adaptive radiation. Despite the economical and ecological importance of the grasshoppers, we currently do not know the phylogenetic relationships among the major lineages. Therefore, there needs to be a collective effort to resolve these issues.

With advances in sequencing technologies (Shendure and $\mathrm{Ji}, 2008$ ), a new approach to phylogenetic studies utilizing whole genome and transcriptome data, also known as phylogenomics, is becoming increasingly popular (Faircloth et al., 2012; Lemmon et al., 2012). For Orthoptera, however, phylogenomic studies currently remain a challenge because the order is known to have the largest nuclear genome size among insects (Hanrahan and Johnston, 2011) ranging from 1.52 to $16.56 \mathrm{~Gb}$ (Gregory, 2014). So far, the migratory locust, Locusta migratoria, is the only orthopteran to be sequenced and its genome is $6.5 \mathrm{~Gb}$ in size (Wang et al., 2014). Unfortunately, this genome is not fully annotated and there is currently no reference genome for any orthopteran, which makes gene annotation for any shotgun sequencing or RNA-seq very difficult. Yet, we remain hopeful that these challenges will be soon overcome with rapidly evolving sequencing technologies and bioinformatics, and we look forward to having a much more thorough understanding about the evolution of this fascinating group of insects.

\section{Acknowledgements}

We thank the Insect Genomic Collection of M. L. Bean Museum at Brigham Young University for 
providing a large number of DNA-grade tissue samples used for this study. Additional valuable specimens were provided by: Corinna Bazelet, Battal Çiplak, Wei-an Deng, Mario Elgueta, David Gray, Claudia Hemp, Taewoo Kim, Michel Lecoq, Norman Penny, Michael Picker, Tony Robillard, Lauren Spearman, Kate Umbers, and Amy Vandergast. Fieldwork to South Africa and Australia was conducted by the senior author under permit numbers CRO 177/08CR and CRO 178/08CR (Eastern Cape) and a license number SF007010 (Western Australia). A large number of students have contributed to molecular data generation throughout the duration of this project: Gabriella Alava, Beka Buckman, Reshley Dalisay, Corina DeLeon, Dan Fenn, Kevin Hiatt, Dana Jensen, Jessica Jensen, Daniel Kaonohi, James Leavitt, Nathan Mahler, Matthew Moulton, Joey Mugleston, and Keone Young. We thank Piotr Naskrecki, Hartmut Wisch, Robert A. Behrstock, Kurt Orion G, and Paul Lenhart for allowing us to use their macrophotographs in the figures. We also thank Ji-Min Noh for illustrations used in the figure, and Derek A. Woller for reviewing an early draft of the manuscript and for assisting with figures. In 2010, Christiane Amédégnato, who contributed a large number of Neotropical grasshoppers to this project, passed away. She was one of the most important acridologists in the 20th century, and we have chosen to honour her through an authorship for her lifetime of dedication to Orthoptera research. This work was supported by the U.S. National Science Foundation (grant numbers DEB0816962 to H.S. and M.F.W. and IOS-1253493 to H.S.).

\section{References}

Alexander, R.D., 1968. Life cycle origins, speciation, and related phenomena in crickets. Q. Rev. Biol. 43, 1-41.

Alfaro, M.E., Santini, F., Brock, C., Alamillo, H., Dornburg, A., Rabosky, D.L., Carnevale, G., Harmon, L.J., 2009. Nine exceptional radiations plus high turnover explain species diversity in jawed vertebrates. Proc. Natl Acad. Sci. USA 106, 1341013414.

Amédégnato, C., 1974. Les genres d'acridiens neotropicaux, leur classification par familles, sous-familles et tribus. Acrida 3, 193203.

Ander, K., 1939. Vergleichend-Anatomische und Phylogenetische Studien über die Ensifera (Saltatoria). Opusc. Entomol. Suppl. 2, $1-306$.

Baccetti, B.M. (Ed)., 1987. Evolutionary Biology of Orthopteroid Insects. Ellis Horwood Limited, Chichester.

Bender, M.L., 2013. Paleoclimate. Princeton University Press, Princeton, NJ.

Bergsten, J., 2005. A review of long-branch attraction. Cladistics 21, 163-193.

Bernt, M., Donath, A., Jühling, F., Externbrink, F., Florentz, C., Fritzsch, G., Pütz, J., Middendorf, M., Stadler, P.F., 2013. MITOS: improved de novo metazoan mitochondrial genome annotation. Mol. Phylogenet. Evol. 69, 313-319.

Bethoux, O., Nel, A., Lapeyrie, J., Gand, G., Galtier, J., 2002. Raphogla rubra gen. n., sp. n., the oldest representative of the clade of modern Ensifera (Orthoptera: Tettigoniidae, Gryllidea). Eur. J. Entomol. 99, 111-116.

Blackith, R.E., Blackith, R.M., 1968. A numerical taxonomy of orthopteroid insects. Aust. J. Zool. 16, 111-131.

Boore, J.L., 1999. Animal mitochondrial genomes. Nucleic Acids Res. 27, 1767-1780.

Brongniart, C., 1885. Les insectes fossiles des terrains primaires. Coup d'oeil rapide sur la faune entomologique des terrains paleozoiques. Bull. Soc. Amis Sci. Nat. Rouen, serie 3, 21.

Cameron, S.L., 2014a. How to sequence and annotate insect mitochondrial genomes for systematic and comparative genomics research. Syst. Entomol. 39, 400-411.

Cameron, S.L., 2014b. Insect mitochondrial genomics: implications for evolution and phylogeny. Annu. Rev. Entomol. 59, 95-117.

Cameron, S.L., Barker, S.C., Whiting, M.F., 2006. Mitochondrial genomics and the new insect order Mantophasmatodea. Mol. Phylogenet. Evol. 38, 274-279.

Castresana, J., 2000. Selection of conserved blocks from multiple alignments for their use in phylogenetic analysis. Mol. Biol. Evol. $17,540-552$.

Chapman, R.F., Joern, A. (Eds.) 1990. Biology of Grasshoppers. John Wiley \& Sons, New York.

Chapman, R.F., Page, W.W., McCaffery, A.R., 1986. Bionomics of the variegated grasshopper (Zonocerus variegatus) in West and Central Africa. Annu. Rev. Entomol. 31, 479-505.

Chintauan-Marquier, I., Legendre, F., Hugel, S., Robillard, T., Grandcolas, P., Nel, A., Zuccon, D., Desutter-Grandcolas, L., 2015. Laying the foundations of evolutionary and systematic studies in crickets (Insecta, Orthoptera): a multilocus phylogenetic analysis. Cladistics. DOI : 10.1111/cla.12114.

Chopard, L. 1920. Recherches sur la conformation et le développement des derniers segments abdominaux chez les Orthoptères. Thèse de la Faculté des Sciences de Paris., Rennes: Imprimerie Oberthur.

Chopard, L. 1949. Ordres des Orthoptères. In: Grassé, P.P. (Ed.), Traité de Zoologie. Masson, Paris, pp. 617-722.

Clary, D.O., Wolstenhome, D.R., 1985. The mitochondrial DNA molecule of Drosophila yakuba: nucleotide sequence, gene organization, and genetic code. J. Mol. Evol. 22, 252-271.

Descamps, M., 1973a. Notes préliminaires sur les genitalia de Proscopoidea (Orthoptera Acridomorpha). Acrida 2, 77-95.

Descamps, M., 1973b. Révision des Eumastacoidea (Orthoptera) aux échelons des familles et des sous-familles (genitalia, répartition, phylogenie). Acrida 2, 161-298.

Desutter-Grandcolas, L., 2003. Phylogeny and the evolution of acoustic communication in extant Ensifera (Insecta, Orthoptera). Zool. Scr. 32, 525-561.

Ding, F.M., Shi, H.W., Huang, Y., 2007. Complete mitochondrial genome and secondary structures of lrRNA and srRNA of Atractomorpha sinensis (Orthoptera, Pyrgomorphidae). Zool. Res. $28,580-588$.

Dirsh, V.M., 1952. The restroration of the subfamily Trigonopteryginae Walker (Orthoptera, Acrididae). Ann. Mag. Nat. Hist. 5, 82-84.

Dirsh, V.M., 1955. Tanaoceridae and Xyronotidae: two new families of Acridoidea (Orthoptera). Ann. Mag. Nat. Hist. 8, 285-288.

Dirsh, V.M., 1957. The spermatheca as a taxonomic character in Acridoidea (Orthoptera). Proc. R. Entomol. Soc. Lond. Ser. A Gen. Entomol. 32, 107-114.

Dirsh, V.M., 1961. A preliminary revision of the families and subfamilies of Acridoidea (Orthoptera, Insecta). Bull. Br. Mus. (Nat. Hist.) Entomol. 10, 351-419.

Dirsh, V.M., 1965. Revision of the family Pneumoridae (Orthoptera: Acridoidea). Bull. Br. Mus. (Nat. Hist.) Entomol. 15, 325-396.

Dirsh, V.M., 1973. Genital organs in Acridomorphoidea (Insecta) as taxonomic character. Z. Zool. Syst. Evol.-Forsch. 11, 133-154.

Dirsh, V.M., 1975. Classification of the Acridomorphoid Insects. E.W. Classey Ltd., Faringdon.

Dirsh, V.M., Mason, J.B., 1979. Systematic and phylogenetic postion of the family Xyronotidae (Acridomorpha, Insecta). Z. Zool. Syst. Evol.-Forsch. 17, 201-210. 
Dixon, A.P., Faber-Langendoen, D., Josse, C., Morrison, J., Loucks, C.J., 2014. Distribution mapping of world grassland types. J. Biogeogr. 41, 2003-2019.

Drummond, A.J., Suchard, M.A., Xie, D., Rambaut, A., 2012. Bayesian Phylogenetics with BEAUti and the BEAST 1.7. Mol. Biol. Evol. 29, 1969-1973.

Eades, D.C., 2000. Evolutionary relationships of phallic structures of Acridomorpha (Orthoptera). J. Orthoptera. Res. 9, 181-210.

Eades, D.C., Otte, D., Cigliano, M.M., Braun, H. 2014. Orthoptera Species File. Version 5.0/5.0. [8/1/2014]. http:// Orthoptera.SpeciesFile.org.

Edgar, R.C., 2004. MUSCLE: multiple sequence alignment with high accuracy and high throughput. Nucleic Acids Res. 32, 17921797.

Erler, S., Ferenz, H., Moritz, R.F.A., Kaatz, H., 2010. Analysis of the mitochondrial genome of Schistocerca gregaria gregaria (Orthoptera: Acrididae). Biol. J. Linn. Soc. 99, 296-305.

Faircloth, B.C., McCormack, J.E., Crawford, N.G., Harvey, M.G., Brumfield, R.T., Glenn, T.C., 2012. Ultraconserved elements anchor thousands of genetic markers spanning multiple evolutionary timescales. Syst. Biol. 61, 717-726.

Felsenstein, J., 1978. Cases in which parsimony or compatibility methods will be positively misleading. Syst. Zool. 27, 401-410.

Fenn, J.D., Cameron, S.L., Whiting, M.F., 2007. The complete mitochondrial genome sequence of the Mormon cricket (Anabrus simplex: Tettigoniidae: Orthoptera) and an analysis of control region variability. Insect Mol. Biol. 16, 239-252.

Fenn, J.D., Song, H., Cameron, S.L., Whiting, M.F., 2008. A mitochondrial genome phylogeny of Orthoptera (Insecta) and approaches to maximizing phylogenetic signal found within mitochondrial genome data. Mol. Phylogenet. Evol. 49, 59-68.

Flook, P., Rowell, H., 1995. Homoplastic rearrangements in insect mitochondrial tRNA genes. Naturwissenschaften 82, 336-337.

Flook, P.K., Rowell, C.H.F., 1997. The phylogeny of the Caelifera (Insecta, Orthoptera) as deduced from mtrRNA gene sequences. Mol. Phylogenet. Evol. 8, 89-103.

Flook, P.K., Rowell, C.H.F., Gellissen, G., 1995. The sequence, organization, and evolution of the Locusta migratoria mitochondrial genome. J. Mol. Evol. 41, 928-941.

Flook, P.K., Klee, S., Rowell, C.H.F., 1999. Combined molecular phylogenetic analysis of the Orthoptera (Arthropoda, Insecta) and implications for their higher systematics. Syst. Biol. 48, 233253.

Flook, P.K., Klee, S., Rowell, C.H.F., 2000. Molecular phylogenetic analysis of the Pneumoroidea (Orthoptera, Caelifera): molecular data resolve morphological character conflicts in the basal Acridomorpha. Mol. Phylogenet. Evol. 15, 345-354.

Gangwere, S.K., Muralirangan, M.C., Muralirangan, M. (Eds.) 1997. The Bionomics of Grasshoppers, Katydids, and Their Kin. CAB International, New York.

Goloboff, P.A., 1999. Analyzing large data sets in reasonable times: solutions for composite optima. Cladistics 15, 415-428.

Goloboff, P.A., Farris, J.S., Nixon, K.C. 2003. T.N.T.: Tree Analysis Using New Technology. Program and documentation, available from the authors, and at www.zmuc.dk/public/ phylogeny.

Gorochov, A.V., 1995a. Contribution to the system and evolution of the order Orthoptera. Zool. Zh. 74, 39-45.

Gorochov, A.V., 1995b. System and evolution of the suborder Ensifera (Orthoptera). Part 1. Trudy Zool. Inst. Akad. Nauk $260,1-224$

Gorochov, A.V. 2001. The higher classification, phylogeny and evolution of the superfamily Stenopelmatoidea. In: Field, L.H. (Ed.) Biology of Wetas, King Crickets and Their Allies. CABI Publishing, Cambridge, MA, pp. 3-33.

Gorochov, A.V., 2012. Systematics of the American katydids (Orthoptera: Tettigoniidae). Communication 1. Proceedings ZIN 316, 3-21.

Grant, H.J., Rentz, D.C.F., 1967. A biosystematic review of the family Tanaoceridae including a comparative study of the proventriculus. Pan-Pac. Entomol. 43, 65-74.
Greenfield, M.D. 1997. Acoustic communication in Orthoptera. In: Gangwere, S.K., Muralirangan, M.C., Muralirangan, M. (Eds.), The Bionomics of Grasshoppers, Katydids and Their Kin. CAB International, Wallingford, pp. 197-230.

Gregory, T.R. 2014. Animal Genome Size Database. http:// www.genomesize.com.

Grimaldi, D., Engel, M.S., 2005. Evolution of the Insects. Cambridge University Press, New York.

Gurney, A.B., 1976. Book Review: classification of the Acridomorphoid Insects. Bull. Entomol. Soc. Am. 22, 30.

Gwynne, D.T., 1995. Phylogeny of the Ensifera (Orthoptera): a hypothesis supporting multiple origins of acoustical signalling, complex spermatophores and maternal care in crickets, katydids, and weta. J. Orthoptera. Res. 4, 203-218.

Gwynne, D.T., 2001. Katydids and Bush-Crickets: Reproductive Behavior and Evolution of the Tettigoniidae. Cornell University Press, Ithaca, NY.

Hanrahan, S.J., Johnston, J.S., 2011. New genome size estimates of 134 species of arthropods. Chromosome Res. 19, 809-823.

Heads, S.W., Leuzinger, L., 2011. On the placement of the Cretaceous orthopteran Brauckmannia groeningae from Brazil, with notes on the relationships of Schizodactylidae (Orthoptera, Ensifera). ZooKeys 77, 17-30.

Heller, K.-G., Hemp, C., Liu, C., Volleth, M., 2014. Taxonomic, bioacoustic and faunistic data on a collection of Tettigonioidea from Eastern Congo (Insecta: Orthoptera). Zootaxa 3785, 343-376.

Ho, S.Y.W., 2007. Calibrating molecular estimates of substitution rates and divergence times in birds. J. Avian Biol. 38, 409-414.

Hugel, S., 2005. Redécouverte du genre Pygacris à l'île de la Réunion: description du mâle de $P$. descampi Kevan, 1975 (Orthoptera, Caelifera). Bull. Soc. Entomol. Fr. 110, 153-159.

Isley, F.B., 1944. Correlation between mandibular morphology and food specificity in grasshoppers. Ann. Entomol. Soc. Am. 37, 4767.

Jost, M.C., Shaw, K.L., 2006. Phylogeny of Ensifera (Hexapoda: Orthoptera) using three ribosomal loci, with implications for the evolution of acoustic communication. Mol. Phylogenet. Evol. 38, $510-530$.

Judd, W.W., 1947. A comparative study of the proventriculus of orthopteroid insects with reference to its use in taxonomy. Can. J. Res. 26, 93-159.

Katoh, K., Kuma, K., Toh, H., Miyata, T., 2005. MAFFT version 5: improvement in accuracy of multiple sequence alignment. Nucleic Acids Res. 33, 511-518.

Kevan, D.K.M., 1976. Book Review: classification of the Acridomorphoid Insects. S. Afr. J. Sci. 72, 316-319.

Kevan, D.K.M. 1982. Orthoptera. In: Parker, S.P. (Ed.) Synopsis and Classification of Living Organisms. McGraw-Hill Book Company, Inc., New York, pp. 352-383.

Kevan, D.K.M., Akbar, S.S., 1964. The Pyrgomorphidae (Orthoptera: Acridoidea): their systematics, tribal divisions and distribution. Can. Entomol. 96, 1505-1536.

Kristensen, N.P. 1991. Phylogeny of extant hexapods. In: Naumann, I.D. (Ed.) The Insects of Australia. Cornell University Press, Ithaca, NY, pp. 125-140.

Lande, R., 1981. Models of speciation by sexual selection on polygenic traits. Proc. Natl Acad. Sci. USA 78, 3721-3725.

Lanfear, R., Calcott, B., Ho, S.Y.W., Guindon, S., 2012. PartitionFinder: combined selection of partitioning schemes and substitution models for phylogenetic analyses. Mol. Biol. Evol. 29, 1695-1701.

Leavitt, J.R., Hiatt, K.D., Whiting, M.F., Song, H., 2013. Searching for the optimal data partitioning strategy in mitochondrial phylogenomics: a phylogeny of Acridoidea (Insecta: Orthoptera: Caelifera) as a case study. Mol. Phylogenet. Evol. 67, 494-508.

Legendre, F., Robillard, T., Song, H., Whiting, M.F., DesutterGrandcolas, L., 2010. One hundred years of instability in ensiferan relationships. Syst. Entomol. 35, 475-488.

Lemmon, A.R., Emme, S.A., Lemmon, E.M., 2012. Anchored hybrid enrichment for massively high-throughput phylogenomics. Syst. Biol. 61, 727-744. 
Letunic, I., Bork, P., 2011. Interactive Tree Of Life v2: online annotation and display of phylogenetic trees made easy. Nucleic Acids Res. 39, W475-W478.

Liu, C., Chang, J., Ma, C., Li, L., Zhou, S., 2013. Mitochondrial genomes of two Sinochlora species (Orthoptera): novel genome rearrangements and recognition sequence of replication origin. BMC Genom. 14, 114.

Ma, C., Liu, C., Yang, P., Kang, L., 2009. The complete mitochondrial genomes of two band-winged grasshoppers, Gastrimargus marmoratus and Oedaleus asiaticus. BMC Genom. $10,1-12$

Maddison, D.R., Maddison, W.P., 2005. MacClade 4. Sinauer Associates, Inc., Sunderland, MA.

Matt, S., Flook, P.K., Rowell, C.H.F., 2008. A partial molecular phylogeny of the Eumastacoidea s. lat. (Orthoptera, Caelifera). J. Orthoptera. Res. 17, 43-55.

Mendelson, T.C., Shaw, K.L., 2005. Rapid speciation in an arthropod. Nature 433, 375-376.

Miller, M.A., Holder, M.T., Vos, R., Midford, P.R., Liebowitz, T., Chan, L., Hoover, P., Warnow, T. 2011. The CIPRES Portals. CIPRES. http://www.phylo.org/sub_sections/portal.

Montealegre-Z, F., 2009. Scale effects and constraints for sound production in katydids (Orthoptera: Tettigoniidae): generator morphology constrains signal parameters. J. Evol. Biol. 22, 355366.

Mugleston, J.D., Song, H., Whiting, M.F., 2013. A century of paraphyly: a molecular phylogeny of katydids (Orthoptera: Tettigoniidae) supports multiple origins of leaf-like wings. Mol. Phylogenet. Evol. 69, 1120-1134.

Nickle, D.A., Castner, J.L., 1995. Strategies utilized by katydids (Orthoptera: Tettigoniidae) against diurnal predators in rainforests of northeastern Peru. J. Orthoptera. Res. 4, 75-88.

Nickle, D.A., Naskrecki, P.A. 1997. Recent developments in the systematics of Tettigoniidae and Gryllidae. In: Gangwere, S.K., Muralirangan, M.C., Muralirangan, M. (Eds.), The Bionomics of Grasshoppers, Katydids and Their Kin. CAB International, New York, pp. 41-58.

Nixon, K.C., 1999. The parsimony ratchet, a new method for rapid parsimony analysis. Cladistics 15, 407-414.

Otte, D., 1992. Evolution of cricket songs. J. Orthoptera. Res. 1, 2549.

Otte, D., Spearman, L., Stiewe, M.B.D., Eades, D.C. 2014. Mantodea Species File Online. Version 5.0/5.0. [8/1/2014]. http:// Mantodea.SpeciesFile.org.

Pascoal, S., Cezard, T., Eik-Nes, A., Gharbi, K., Majewska, J., Payne, E., Ritchie, M.G., Zuk, M., Bailey, N.W., 2014. Rapid convergent evolution in wild crickets. Curr. Biol. 24, 1369-1374.

Pener, M.P., Simpson, S.J., 2009. Locust phase polyphenism: an update. Adv. In Insect Phys. 36, 1-286.

Ragge, D.R., 1955. The Wing-Venation of the Orthoptera Saltatoria, With Notes on Dictyopteran Wing-Venation. British Museum of Natural History, London.

Ragge, D.R., 1977. Classificatin of the Tettigonioidea. Lyman Entomol. Mus. Res. Lab. Mem. 4, 44-46.

Rambaut, A. 2006-2009. FigTree: Tree Figure Drawing Tool Version 1.3.1.

Rambaut, A., Charleston, M. 2001. TreeEdit: Phylogenetic Tree Editor v1.0 alpha 8.

Rambaut, A., Drummond, A.J. 2002-2013a. LogCombiner v1.8.0.

Rambaut, A., Drummond, A.J. 2002-2013b. TreeAnnotator v1.8.0.

Rambaut, A., Drummond, A.J. 2003-2009. Tracer: MCMC Trace Analysis Tool Version v1.5.0.

Rehn, J.A.G., 1948. The locust genus Tanaocerus as found in the United States, and the description of a related new genus (Orthoptera: Acridoidea). Proc. Acad. Nat. Sci. Phila. 100, 1-22.

Rehn, J.A.G., Hebard, M., 1912. A revision of the genera and species of the group Mogoplistii (Orthoptera: Gryllidae) found in North America north of the Isthmus of Panama. Proc. Acad. Nat. Sci. Phil. 64, 184-234.

Riek, E.F., 1976. New Upper Permian insects from Natal, South Africa. Ann. Natal Museum 22, 755-789.
Roberts, H.R., 1941. A comparative study of the subfamilies of the Acrididae (Orthoptera) primarily on the bases of their phallic structures. Proc. Acad. Nat. Sci. Phil. 93, 201-246.

Robillard, T., Grandcolas, P., Desutter-Grandcolas, L., 2007. A shift toward harmonics for high-frequency calling shown with phylogenetic study of frequency spectra in Eneopterinae crickets (Orthoptera, Grylloidea, Eneopteridae). Can. J. Zool. 85, 1264 1275.

Rowell, C.H.F., 1967. Experiments on aggregations of Phymateus purpurascens (Orthoptera, Acrididae, Pyrgomorphidae). J. Zool. (Lond.) 152, 179-193.

Scudder, S.H. 1885. Insecta. In: Zittel, K.A. (Ed.) Handbuch der Palaeontologie. 1. Abtheilung; 2. Band, Mollusca und Arthropoda. R. Oldenbourg, München and Leipzig, pp. 747-831.

Sharov, A.G., 1968. Phylogeny of the Orthopteroidea. Trudy Paleont. Inst. 118, 1-216.

Sheffield, N.C., Hiatt, K.D., Valentine, M.C., Song, H., Whiting, M.F., 2010. Mitochondrial genomics in Orthoptera using MOSAS. Mitochondrial DNA 21, 87-104.

Shendure, J., Ji, H., 2008. Next-generation DNA sequencing. Nat. Biotechnol. 26, 1135-1145.

Shi, H.W., Ding, F.M., Huang, Y., 2008. Complete sequencing and analysis of mtDNA in Phlaeoba albonema Zheng. Chin. J. Biochem. 24, 604-611.

Shimodaira, H., 2002. An approximately unbiased test of phylogenetic tree selection. Syst. Biol. 51, 492-508.

Shimodaira, H., Hasegawa, M., 1999. Multiple comparisons of loglikelihoods with applications to phylogenetic inference. Mol. Biol. Evol. 16, 1114-1116.

Shimodaira, H., Hasegawa, M., 2001. CONSEL: for assessing the confidence of phylogenetic tree selection. Bioinformatics 17, 1246-1247.

Slifer, E.H., 1939. The internal genitalia of female Acridinae, Oedipodinae and Pauliniinae (Orthoptera, Acrididae). J. Morphol. 65, 437-469.

Soltis, D.E., Soltis, P.S., Endress, P.K., Chase, M.W., 2005. Phylogeny and Evolution of Angiosperms. Sinauer, Sunderland, MA.

Song, H., 2010. Grasshopper systematics: past, present and future. J. Orthoptera. Res. 19, 57-68.

Song, H., Mariño-Pérez, R., 2013. Re-evaluation of taxonomic utility of male phallic complex in higher-level classification of Acridomorpha (Orthoptera: Caelifera). Insect Syst. Evol. 44, 241-260.

Song, H., Sheffield, N.C., Cameron, S.L., Miller, K.B., Whiting, M.F., 2010. When phylogenetic assumptions are violated: the effect of base compositional heterogeneity and among-site rate variation in beetle mitochondrial phylogenomics. Syst. Entomol. $35,429-448$.

Spooner, J.D., 1973. Sound production in Cyphoderris monstrosa (Orthoptera: Prophalangopsidae). Ann. Entomol. Soc. Am. 66, 4-5.

Stamatakis, A., Hoover, P., Rougemont, J., 2008. A Rapid Bootstrap Algorithm for the RAxML Web-Servers. Syst. Biol. 75, 758-771.

Stocsits, R.R., Letsch, H., Hertel, J., Misof, B., Stadler, P.F., 2009. Accurate and efficient reconstruction of deep phylogenies from structured RNAs. Nucleic Acids Res. 37, 6184-6193.

Storozhenko, S.Y. 1997. Fossil history and phylogeny of orthopteroid insects. In: Gangwere, S.K., Muralirangan, M.C., Muralirangan, M. (Eds.), The Bionomics of Grasshoppers, Katydids and Their Kin. CAB International, Wallingford, pp. 59-82.

Strömberg, C.A.E., 2011. Evolution of grasses and grassland ecosystems. Annu. Rev. Earth Planet. Sci. 39, 517-544.

Sun, H.M., Zheng, Z.M., Huang, Y., 2010. Sequence and phylogenetic analysis of complete mitochondrial DNA of two grasshopper species Gomphocerus rufus (Linnaeus, 1758) and Primnoa arctica (Zhang \& Jin, 1985) (Orthoptera: Acridoidea). Mitochondrial DNA 21, 115-131.

Svenson, G.J., Whiting, M.F., 2004. Phylogeny of Mantodea based on molecular data: evolution of a charismatic predator. Syst. Entomol. 29, 359-370. 
Tamura, K., Peterson, D., Peterson, N., Stecher, G., Nei, M., Kumar, S., 2011. MEGA5: molecular evolutionary genetics analysis using maximum likelihood, evolutionary distance, and maximum parsimony methods. Mol. Biol. Evol. 28, 2731-2739.

Uvarov, B.P., 1966. Grasshoppers and Locusts, Vol. 1. Cambridge University Press, Cambridge.

Uvarov, B.P., 1977. Grasshoppers and Locusts, Vol. 2. Centre for Overseas Pest Research, London.

Vickery, V.R., 1977. Taxon ranking in Grylloidea and Gryllotalpoidea. Lyman Entomol. Mus. Res. Lab. Mem. 4, 1-31.

Vickery, V.R. 1997. Classification of the Orthoptera (sensu stricto) or Caelifera. In: Gangwere, S.K., Muralirangan, M.C., Muralirangan, M. (Eds.), The Bionomics of Grasshoppers, Katydids and Their Kin. CAB International, Wallingford, pp. 5-40.

Vickery, V.R., Kevan, D.K.M., 1983. A monograph of the orthopteroid insects of Canada and adjacent regions. Lyman Entomol. Mus. Res. Lab. Mem. 13, 711-728.

Wang, X., Fang, X., Yang, P., Jiang, X., Jiang, F., Zhao, D., Li, B., Cui, F., Wei, J., Ma, C., Wang, Y., He, J., Luo, Y., Wang, Z., Guo, X., Guo, W., Zhang, Y., Yang, M., Hao, S., Chen, B., Ma, Z., Yu, D., Xiong, Z., Zhu, Y., Fan, D., Han, L., Wang, B., Chen, Y., Wang, J., Yang, L., Zhao, W., Feng, Y., Chen, G., Lian, J., Li, Q., Huang, Z., Yao, X., Lv, N., Zhang, G., Li, Y., Zhu, B., Kang, L., 2014. The locust genome provides insight into swarm formation and long-distance flight. Nat. Commun. 5, 2957.

West-Eberhard, M.J., 1983. Sexual selection, social competition, and speciation. Q. Rev. Biol. 58, 155-183.

Whiting, M.F., 2002. Phylogeny of the holometabolous insect orders: molecular evidence. Zool. Scr. 31, 3-17.

Whiting, M.F., Bradler, S., Maxwell, T., 2003. Loss and recovery of wings in stick insects. Nature 421, 264-267.

Whitman, D.W. 1991. Grasshopper chemical communication. In: Chapman, R.F., Joern, A. (Eds.), Biology of Grasshoppers. John Wiley \& Sons, New York, pp. 357-391.

Wolff, J.N., Shearman, D.C.A., Brooks, R.C., Ballard, J.W.O., 2012. Selective enrichment and sequencing of whole mitochondrial genomes in the presence of nuclear encoded mitochondrial pseudogenes (numts). PLoS ONE 7, e37142.

Xiao, B., Feng, X., Miao, W.J., Jiang, G.F., 2012a. The complete mitochondrial genome of grouse locust Tetrix japonica (Insecta: Orthoptera: Tetrigoidea). Mitochondrial DNA 23, 288-289.

Xiao, B., Chen, W., Hu, C.C., Jiang, G.F., 2012b. Complete mitochondrial genome of the groundhopper Alulatettix yunnanensis (Insecta: Orthoptera: Tetrigoidea). Mitochondrial DNA 23, 286-287.

Yang, H., Huang, Y., 2011. Analysis of the complete mitochondrial genome sequence of Pielomastax zhengi. Zool. Res. 32, 353-362.

Yang, M.R., Zhou, Z.J., Chang, Y.L., Zhao, L.H., 2012. The mitochondrial genome of the quite-calling katydids, Xizicus fascipes (Orthoptera: Tettigoniidae: Meconematinae). J. Genet. 91, 141-153.

Ye, W., Dang, J., Xie, L., Huang, Y., 2008. Complete mitochondrial genome of Teleogryllus emma (Orthoptera: Gryllidae) with a new gene order in Orthoptera. Zool. Res. 29, 236-244.

Yin, H., Zhi, Y., Jiang, H., Wang, P., Yin, X., Zhang, D., 2011. The complete mitochondrial genome of Gomphocerus tibetanus Uvarov, 1935 (Orthoptera: Acrididae: Gomphocerinae). Gene 494, 214-218.
Zeuner, F.E, 1937. Descriptions of new genera and species of fossil Saltatoria (Orthoptera). Proc. R. Entomol. Soc. Lond. Ser. B. Taxon. 6, 154-159.

Zeuner, F.E., 1939. Fossil Orthoptera Ensifera. British Museum (Natural History), London.

Zeuner, F.E., 1942. The Locustopsidae and the phylogeny of the Acridodea (Orthoptera). Proc. R. Entomol. Soc. Lond. Ser. B Taxon. 11, 1-18.

Zhang, C.Y., Huang, Y., 2008. Complete mitochondrial genome of Oxya chinensis (Orthoptera, Acridoidea). Acta Biochim. Biophys. Sin. 40, 7-18.

Zhang, D., Zhi, Y., Yin, H., Li, X., Yin, X., 2011. The complete mitochondrial genome of Thrinchus schrenkii (Orthoptera: Caelifera, Acridoidea, Pamphagidae). Mol. Biol. Rep. 38, 611619.

Zhang, H., Huang, Y., Lin, L., Wang, X., Zheng, Z., 2013a. The phylogeny of the Orthoptera (Insecta) as deduced from mitogenomic gene sequences. Zool. Stud. 52, 37.

Zhang, H.L., Zeng, H.H., Huang, Y., Zheng, Z.M., 2013b. The complete mitochondrial genomes of three grasshoppers, Asiotmethis zacharjini, Filchnerella helanshanensis and Pseudotmethis rubimarginis (Orthoptera: Pamphagidae). Gene 517, 89-98.

Zhao, L., Zheng, Z.M., Huang, Y., Sun, H.M., 2010. A comparative analysis of mitochondrial genomes in Orthoptera (Arthropoda: lnsecta) and genome descriptions of three grasshopper species. Zool. Sci. 27, 662-672.

Zhou, Z., Huang, Y., Shi, F., 2007. The mitochondrial genome of Ruspolia dubia (Orthoptera: Conocephalidae) contains a short A+T-rich region of $70 \mathrm{bp}$ in length. Genome 50, 855866.

Zhou, Z., Shi, F., Huang, Y., 2008. The complete mitogenomeof the Chinese bush cricket, Gampsocleis gratiosa (Orthoptera: Tettigonioidea). J. Genet. Genomics 35, 341-348.

Zhou, Z., Huang, Y., Shi, F., Ye, H., 2009. The complete mitochondrial genome of Deracantha onos (Orthoptera: Bradyporidae). Mol. Biol. Rep. 36, 7-12.

Zhou, Z., Ye, H., Huang, Y., Shi, F., 2010. The phylogeny of Orthoptera inferred from mtDNA and description of Elimaea cheni (Tettigoniidae: Phaneropterinae) mitogenome. J. Genet. Genomics 37, 315-324.

Zhou, Z., Yang, M., Chang, Y., Shi, F., 2013. Comparative analysis of mitochondrial genomes of two long-legged katydids (Orthoptera: Tettigoniidae). Acta Entomol. Sinica. 56, 408-418.

Zhou, Z., Shi, F., Zhao, L., 2014. The first mitochondrial genome for the superfamily Hagloidea and implications for its systematic status in Ensifera. PLoS ONE 9, e86027.

\section{Supporting Information}

Additional Supporting Information may be found in the online version of this article:

Table S1. Annotation of newly generated mitochondrial genomes in this study. 